PNL-10818

UC-350

\title{
IMPACT EVALUATION FOR THE MANUFACTURED HOUSING ACQUISITION PROGRAM: TECHNICAL APPENDIX
}
A. D. Lee
Z. T. Taylor
D. W. Schrock
D. C. Kavanaugh
R. I. Chin

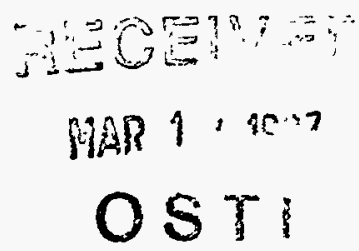

October 1995

Prepared for Sheila Riewer, Office of Marketing, Conservation, and Production Measurement and Evaluation Section the Bonneville Power Administration under a Related Services Agreement with the U.S. Department of Energy Contract DE-ACO6-76RLO 1830

Pacific Northwest Laboratory

Richland, Washington 99352 


\section{DISCLAIMIER}

Portions of this document may be illegible in electronic image products. Images are produced from the best available original document. 


\section{DISCLAIMER}

This report was prepared as an account of work sponsored by an agency of the United States Government. Neither the United States Government nor any agency thereof, nor any of their employees, make any warranty, express or implied, or assumes any legal liability or responsibility for the accuracy, completeness, or usefulness of any information, apparatus, product, or process disclosed, or represents that its use would not infringe privately owned rights. Reference herein to any specific commercial product, process, or service by trade name, trademark, manufacturer, or otherwise does not necessarily constitute or imply its endorsement, recommendation, or favoring by the United States Government or any agency thereof. The views and opinions of authors expressed herein do not necessarily state or reflect those of the United States Government or any agency thereof. 


\section{EXECUTIVE SUMMARY}

This report supplements Lee et al. (1995), which presents the findings of an impact evaluation of the Manufactured Housing Acquisition Program (MAP). Pacific Northwest Laboratory conducted the evaluation and prepared both reports.

This report presents detailed technical information relevant to the MAP impact evaluation. It is intended to provide the interested reader with enough information to answer most technical questions about the analysis and results.

\section{TIERED ANALYSIS APPROACH}

We used a three-tiered process to analyze the energy consumption of both MAP and baseline homes. The information from each analysis was useful for designing our final analysis.

The first approach was a comparison of annual billing data, followed by a simplified regression analysis to adjust for major home characteristics. We compared the mean annual kWh consumption of MAP and baseline homes, and used the difference to estimate energy savings. We made no adjustments for long-term weather.

This first analysis showed that MAP homes consumed less electricity than the baseline homes used in our analysis, but the differences were less than the pre-program estimates suggested. We identified several factors to examine further. First, nonelectric supplemental heating was more common in baseline homes than in MAP homes. Second, in some cases heat pumps were more common in baseline homes than MAP homes and they tended to reduce energy consumption. Third, the average baseline home in our sample was smaller than the average MAP home, thus reducing the difference between electricity use in MAP and baseline homes. Fourth, we found that the distribution of total electricity consumption and consumption per square foot in MAP homes exhibited less variance than in baseline homes.

The second-tier approach was an application of the PRInceton Scorekeeping Method (PRISM). This methodology uses monthly billing data to estimate coefficients that can be used to predict the non-temperature- and temperature-sensitive portions of energy consumption. We used PRISM to estimate electricity consumption for a "normal" weather year. 
We used PRISM to analyze several samples. We applied it to billing data for the entire sample of homes, all baseline homes only, and all MAP homes only. We then screened the sample to eliminate observations that could not be modeled well by PRISM, and repeated the analyses. The results showed that the standard errors of the savings estimates declined, in most cases, after the billing data were screened. Screening the data, however, considerably reduced the sample sizes and this tended to diminish the accuracy and precision of all estimates.

The PRISM approach, however, could not be applied effectively to produce the energy savings estimates needed in this analysis. This was because of the confounding effects of non-electric heat, differences in the efficiency baselines of interest, and other factors not addressed by the PRISM approach.

\section{REGRESSION MODEL}

We used a detailed regression analysis to control for a wide range of possible energy consumption determinants such occupant demographics, appliance inventories, and weather. This allowed us to estimate energy savings attributable to the MAP features under different conditions.

This approach was applied to all sample homes for which we obtained billing data. Billing-period (usually monthly) data were used.

Our model used appliance inventories to explain total kWh consumption like a conditional demand analysis (CDA), but was formulated around the anticipated thermal-physical relationships. It included several appliances and the effects of demographic and behavioral variables that were found to be significant. Because differences in heating performance were the primary anticipated effect of MAP, we focused on coefficients for different types of heating systems and combinations of systems in formulating the model.

Several potential limitations of the model are discussed. These include potential difficulties modeling the space-heating response to temperature and the effect of ventilation. Statistical and econometric details of the model are presented. The technique for developing confidence intervals with this model is also discussed. 


\section{COMPARISONS WITH OTHER STUDIES}

We compared our study and results with the pre-program analysis conducted to predict energy savings. The purpose was to help explain differences between preprogram expectations and observed results, and to inform the analysis process so that predictions of future program energy savings might be improved.

The pre-program estimates of MAP savings were based on analyses using the SUNDAY computer program. They were considerably larger than our estimates. The factors most likely to account for the differences included the following: dissimilarities between assumed and actual home sizes, differences in ventilation rates, uncertainties in internal and solar gain assumptions, occurrence of random vacancies, both intentional and implicit zoning of homes, and inaccuracies in modeling temperature setbacks. Several of these effects combined might explain much of the apparent discrepancy between our findings and pre-program estimates.

We also examined and compared our study to one by Regional Economic Research (RER). It analyzed electricity usage in both MAP and control homes within the service territories of three of the region's investor-owned utilities (IOUs). The study employed both engineering estimation and econometric estimation using a conditional demand model. It produced energy savings estimates that were considerably smaller than ours. We identified three possible biases in the RER model that might partially explain the differences.

\section{LEVELIZED COSTS}

We used levelized costs to assess MAP's cost-effectiveness. The approach that we used was published by Bonneville. Bonneville's methodology focuses on regional system cost. We also analyzed cost-effectiveness from Bonneville's system cost perspective, based on the cost of MAP to Bonneville. Using our estimated energy savings and incremental total costs, we calculated the levelized costs of energy savings for MAP homes.

It is important to note that Bonneville's methodology does not address the market transformation effects of programs such as MAP. Trying to account for the effects of market transformation considerably complicates the assessment of program costeffectiveness. Issues of "free riders" and "free drivers" and how they affect different cost-effectiveness tests merit specific attention. 



\section{CONTENTS}

EXECUTIVE SUMMARY $\ldots \ldots \ldots \ldots \ldots \ldots \ldots \ldots \ldots \ldots \ldots \ldots \ldots$ iii

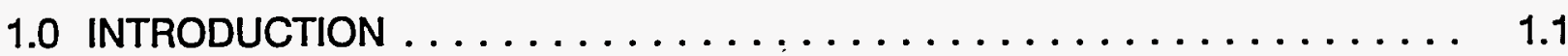

2.0 FIRST-TIER ANALYSIS: SIMPLIFIED BILLING DATA ANALYSIS $\ldots \ldots \ldots 2.1$

2.1 APPROACH AND RESULTS $\ldots \ldots \ldots \ldots \ldots \ldots \ldots \ldots \ldots \ldots .1$

2.2 OBSERVATIONS ABOUT RESULTS $\ldots \ldots \ldots \ldots \ldots \ldots \ldots \ldots$

3.0 SECOND-TIER ANALYSIS: PRISM ANALYSIS $\ldots \ldots \ldots \ldots \ldots \ldots \ldots .1$

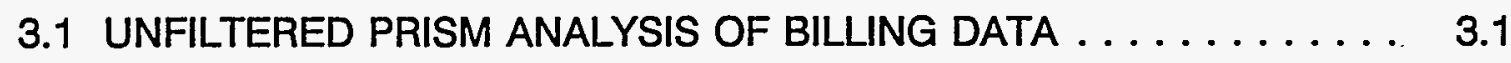

3.2 PRISM ANALYSIS OF STAGE-ONE FILTERED SAMPLE $\ldots \ldots \ldots .3 .6$

3.3 PRISM ANALYSIS OF STAGE-TWO FILTERED SAMPLE $\ldots \ldots \ldots 3.11$

3.4 ADJUSTED PRISM RESULTS $\ldots \ldots \ldots \ldots \ldots \ldots \ldots \ldots \ldots .13$

4.0 THIRD-TIER ANALYSIS: REGRESSION ANALYSIS $\ldots \ldots \ldots \ldots \ldots \ldots .1$

4.1 OVERVIEW OF APPROACH $\ldots \ldots \ldots \ldots \ldots \ldots \ldots \ldots \ldots \ldots .1$

4.2 METHODOLOGY $\ldots \ldots \ldots \ldots \ldots \ldots \ldots \ldots \ldots \ldots \ldots .2$

4.3 SUMMARY OF IMPLIED MAP SAVINGS $\ldots \ldots \ldots \ldots \ldots \ldots \ldots .4$

4.4 DISCUSSION OF REGRESSION COEFFICIENTS $\ldots \ldots \ldots \ldots \ldots 4.11$

4.5 DISCUSSION OF MODELING ISSUES $\ldots \ldots \ldots \ldots \ldots \ldots \ldots .15$

4.6 CONFIDENCE INTERVALS $\ldots \ldots \ldots \ldots \ldots \ldots \ldots \ldots \ldots \ldots \ldots$ 
5.0 REVIEW OF PRE-PROGRAM ANALYSIS

5.1 INTRODUCTION $\ldots \ldots \ldots \ldots \ldots \ldots \ldots \ldots \ldots \ldots \ldots \ldots \ldots . . \ldots \ldots$

5.2 DIFFERENCES BETWEEN PRE-PROGRAM AND PNL ANALYSES . 5.2

5.3 CONCLUSIONS $\ldots \ldots \ldots \ldots \ldots \ldots \ldots \ldots \ldots \ldots \ldots \ldots \ldots \ldots \ldots \ldots \ldots$

6.0 REVIEW OF UTILITY EVALUATION ANALYSIS $\ldots \ldots \ldots \ldots \ldots \ldots . . \ldots$

6.1 OVERVIEW $\ldots \ldots \ldots \ldots \ldots \ldots \ldots \ldots \ldots \ldots \ldots \ldots \ldots .1$

6.2 IMPLICATIONS OF THE UTILITY STUDY APPROACH $\ldots \ldots \ldots .6 .4$

6.3 DISCUSSION OF THE UTILITY STUDY . . . . . . . . . 6.5

6.4 COMPARISON WITH PNL STUDY $\ldots \ldots \ldots \ldots \ldots \ldots \ldots \ldots .8$

6.5 CONCLUSIONS $\ldots \ldots \ldots \ldots \ldots \ldots \ldots \ldots \ldots \ldots \ldots \ldots \ldots \ldots \ldots \ldots$

7.0 LEVELIZED COST ANALYSIS DETAILS $\ldots \ldots \ldots \ldots \ldots \ldots \ldots \ldots$

8.0 REFERENCES $\ldots \ldots \ldots \ldots \ldots \ldots \ldots \ldots \ldots \ldots \ldots \ldots \ldots .1$ 


\section{TABLES}

2.1 Regression Coefficients to Estimate $\mathrm{kWh} /$ year Consumption $\ldots \ldots \ldots \ldots 2.2$

2.2 Regression Coefficients to Estimate $\mathrm{kWh} /$ year $/ \mathrm{ft}^{2}$ Consumption . . . . . 2.2

2.3 Distributions of Raw Electricity Consumption $\ldots \ldots \ldots \ldots \ldots \ldots \ldots$

3.1 PRISM Results for Entire Study Sample, Unfiltered . . . . . . . . . 3.2

3.2 MAP and Baseline Home Energy Use Comparison, Unfiltered $\ldots \ldots \ldots 3.3$

3.3 Energy Use Comparison by PRISM Model, Unfiltered $\ldots \ldots \ldots \ldots .4$

3.4a Energy Use Comparison for $\mathrm{CZ} 1$, Unfiltered $\ldots \ldots \ldots \ldots \ldots . \ldots$

3.4b Energy Use Comparisọn for $\mathrm{CZ} 2$, Unfiltered $\ldots \ldots \ldots \ldots \ldots \ldots$

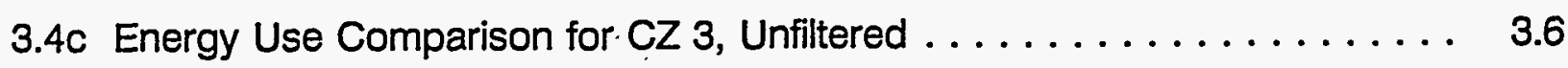

3.5 PRISM Results for Entire Study Sample, Stage-Ọe Filtered . . . . . . . 3.7

3.6 MAP and Baseline Home Energy Use Comparison, Stage-One Filtered . . . 3.8

3.7 Energy Use Comparison by PRISM Model, Stage-One Filtered . . . . . . 3.9

3.8a Energy Use Comparison for $\mathrm{CZ} 1$, Stage-One Filtered $\ldots \ldots \ldots \ldots .9$

3.8b Energy Use Comparison for $\mathrm{CZ} 2$, Stage-One Filtered $\ldots \ldots \ldots \ldots .10$

3.8c Energy Use Comparison for $\mathrm{CZ} 3$, Stage-One Filtered $\ldots \ldots \ldots \ldots .10$

3.9 "Heating" Energy.Sàvings for Stage-One Filtered Analysis $\ldots \ldots \ldots . . .11$

3.10 PRISM Results for Entire Study Sample, Stage-Two Filtered . . . . . . 3.12

3.11 MAP and Baseline Home Energy Use Comparison, Stage-Two Filtered . . 3.13 
3.12 Energy Use Comparison by Climate Zone, Stage-Two Filtered . . . . . 3.14

3.13 "Heating" Energy Savings for Stage-Two Filtered Analysis . . . . . . . . . . 3.14

4.2 Definition of Terms in Equation (4.2) $\ldots \ldots \ldots \ldots \ldots \ldots \ldots \ldots \ldots .7$

4.3 Estimated Coefficients in Equation $(4.2) \ldots \ldots \ldots \ldots \ldots \ldots \ldots \ldots .8$

4.4 Weather Assumptions Used in Sample Home Estimates . . . . . . . . . . 4.9

4.5 Comparison of Regression Model Estimates and Billing Data Without Adjustments, kWh/year .................. 4.10

4.6 Baseline and MAP Home Heating Coefficients by System Type $\ldots \ldots \ldots 4.14$

6.1 Comparative Estimates of MAP Savings $(\mathrm{kWh} / \mathrm{yr}) \ldots \ldots \ldots \ldots . \ldots \ldots$

6.2 Estimated SAE Parameters from IOU Study $\ldots \ldots \ldots \ldots \ldots \ldots \ldots .6$

6.3 Comparison of UEC Estimates (kWh/day) $\ldots \ldots \ldots \ldots \ldots \ldots \ldots . . . \ldots$

7.1 System Cost Adjustments in $\mathrm{c} / \mathrm{kWh}(1993 \$) \ldots \ldots \ldots \ldots \ldots \ldots .1$ 


\subsection{INTRODUCTION}

This document supplements the Manufactured Housing Acquisition Program (MAP) impact evaluation report, Lee et al. (1995). MAP is a voluntary energy-efficiency program for HUD-code manufactured. homes conducted in the Pacific Northwest beginning in April 1992.

Pacific Northwest Laboratory (PNL) prepared this and the impact evaluation reports for the Bonneville Power Administration (Bonneville). ${ }^{(a)}$ Lee et al. (1995) presents the objectives, methodology, and findings of the program evaluation. This report presents more details about specific aspects of the analysis.

We used a three-tier approach to analyze the energy consumption. of MAP and baseline homes. Chapter 2 discusses Tier 1, the billing data and simplified regression analysis. Chapter 3 presents the details of the Tier 2 analysis, the PRInceton Scorekeeping Method (PRISM). Chapter 4 presents details of the primary analysis technique that we used, a comprehensive regression analysis.

Chapters 5 and 6 review two other studies of energy savings associated with MAP. Chapter 5 discusses the simulation model analysis conducted by Ecotope, Inc. Chapter 6 reviews the analysis by Regional Economic Research conducted for three Pacific Northwest investor-owned utilities.

The final chapter, Chapter 7 , presents details of the Bonneville levelized cost methodology. used to estimate the cost of energy savings associated with MAP.

Results are presented and discussed in many cases for the three different climate zones found in the Pacific Northwest. Climate zone 1 has 6,000 or less heatingdegree days (HDD); climate zone 2 has 6,000 to 8,000 HDD; and the coldest zone, climate zone 3 , has more than $8,000 \mathrm{HDD}$. For simplicity, we refer to the three zones as $\mathrm{CZ} 1, \mathrm{CZ} 2$, and $\mathrm{CZ} 3$.

(a) The Pacific Northwest Laboratory is a multiprogram national laboratory operated for the U.S. Department of Energy by Battelle Memorial Institute under contract DE-AC06-76RLO-1830. 


\subsection{FIRST-TIER ANALYSIS: SIMPLIFIED BILLING DATA ANALYSIS}

This section discusses our first-tier analysis. This was a simplified analysis of the annual electricity billing data supplemented with a simple regression analysis to adjust for factors likely to influence electricity consumption.

\subsection{APPROACH AND RESULTS}

We applied the first-tier approach to MAP and baseline home samples for which 12 months of billing data were available. Billing data for the most recent year for individual homes were compiled and used in the analysis. ${ }^{\left({ }^{\circ}\right)}$ Separate databases were developed for MAP and baseline homes in each of the three climate zones. No adjustments were made for long-term weather. The period analyzed was less severe than the long-term weather (heating-degree days, HDD, were below the long-term average for each climate zone), so temperature-sensitive energy consumption was probably less for all the homes than would be typical. In this analysis, data for all homes were combined; all homes were analyzed together regardless of their electric heating system type or the presence, or absence, of air conditioners.

In the initial analysis, we simply calculated the electricity consumption of each home for the selected 1-year period. We calculated the mean consumption by climate zone and home category. The difference between the mean consumption for MAP and baseline homes provided an estimate of energy savings. Chapter 3 of Lee et al. (1995) summarizes these results.

In the second analysis, we estimated simple ordinary least squares regression models for each climate zone. The predictor variables were chosen from a small set of those that were expected to affect electricity consumption and that were readily available. We investigated several specifications for each climate zone and selected one based on the goodness-of-fit, reasonableness of the coefficient values, and residual patterns. Table 2.1 presents the regression coefficients for equations to estimate annual electricity consumption by climate zone. Table 2.2 presents coefficients for equations to estimate annual electricity use per square foot of floor area by climate zone.

(a) Some sample homes had billing data for a 12-month period that fell short of 365 days. These data were extended to 365 days by linear extrapolation of the last billing period. The billing periods did not coincide exactly for individual homes, but they were almost all over the span from April 1992 through March 1993. 
TABLE 2.1. Regression Coefficients to Estimate kWh/year Consumption

\begin{tabular}{|c|c|c|c|c|c|c|}
\hline \multirow[t]{2}{*}{ Variable } & \multicolumn{2}{|c|}{$\mathrm{CZ} 1$} & \multicolumn{2}{|c|}{ CZ 2} & \multicolumn{2}{|c|}{$\mathrm{CZ} 3$} \\
\hline & Value & t-statistic & Value & t-statistic & Value & t-statistic \\
\hline Intercept (kWh/yr) & 4,490 & 2.34 & 2,090 & 0.68 & 3,550 & 0.62 \\
\hline Shell area $\left(\mathrm{ft}^{2}\right)$ & 3.32 & 7.06 & 4.44 & 6.33 & 5.43 & 3.83 \\
\hline $\begin{array}{l}\% \text { of heat supplied by } \\
\text { non-electric fuel }\end{array}$ & -46.8 & -3.15 & -62.8 & -4.24 & -219 & -4.17 \\
\hline Presence of heat pump & $-2,420$ & -2.26 & - & - & - & - \\
\hline Single-section home & - & - & 3,540 & 1.91 & - & - \\
\hline MAP home & $-3,420$ & -4.20 & $-2,900$ & -2.66 & $-5,270$ & -2.17 \\
\hline Adjusted R-square & \multicolumn{2}{|c|}{0.36} & \multicolumn{2}{|c|}{0.39} & \multicolumn{2}{|c|}{0.57} \\
\hline No. of observations & \multicolumn{2}{|c|}{110} & \multicolumn{2}{|c|}{88} & \multicolumn{2}{|c|}{18} \\
\hline
\end{tabular}

TABLE 2.2. Regression Coefficients to Estimate $\mathrm{kWh} / \mathrm{year} / \mathrm{ft}^{2}$ Consumption

\begin{tabular}{|c|c|c|c|c|c|c|}
\hline \multirow[t]{2}{*}{ Variable } & \multicolumn{2}{|c|}{$C Z 1$} & \multicolumn{2}{|c|}{ CZ 2} & \multicolumn{2}{|c|}{$\mathrm{CZ} 3$} \\
\hline & Value & $\mathrm{t}$-statistic & Value & t-statistic & Value & t-statistic \\
\hline Intercept (kWh/yr/ft $)$ & 12.7 & 27.1 & 14.4 & 20.6 & 19.5 & 11.9 \\
\hline $\begin{array}{l}\% \text { of heat supplied by } \\
\text { non-electric fuel }\end{array}$ & -0.0415 & -3.79 & -0.0437 & -4.08 & -0.172 & -4.52 \\
\hline Presence of heat pump & -2.25 & -2.99 & - & - & - & - \\
\hline Single-section home & 3.56 & 4.00 & 6.01 & 5.09 & - & - \\
\hline MAP home & -2.39 & -3.89 & -2.31 & -2.92 & -4.68 & -2.61 \\
\hline Adjusted R-square & \multicolumn{2}{|c|}{0.33} & \multicolumn{2}{|c|}{0.40} & \multicolumn{2}{|c|}{0.52} \\
\hline No. of observations & \multicolumn{2}{|c|}{110} & \multicolumn{2}{|c|}{88.} & \multicolumn{2}{|c|}{18} \\
\hline
\end{tabular}


Probably because of their simplicity, these equations have relatively low R-square values. The coefficients for shell area, percent of non-electric heat, and presence of a heat pump exhibit the expected behavior. Table 2.1 shows that the electricity consumption is less for MAP homes, with all else being equal. The amount of the effect ranges from 2,900 to 5,270 kWh/year for our sample homes. Table 2.2 indicates that single-section homes consume more per square foot of floor area in two of the climate zones. This is consistent with the fact that, given the same floor area, shell area would be larger for single-section than multi-section homes because the single-section homes would be less square. These results indicate that MAP homes use between 2.31 and $4.68 \mathrm{kWh} / \mathrm{year} / \mathrm{ft}^{2}$ of floor area less than our sample of baseline homes.

\subsection{OBSERVATIONS ABOUT RESULTS}

The simple comparison of raw billing data suggests that MAP homes consume less electricity than the baseline homes used in our analysis, but the differences are not as large as pre-program estimates suggested. Looking carefully at the raw billing data and other information collected in this study, several factors were identified that influenced the estimated energy savings attributable to MAP.

First, non-electric supplemental heating was more common in baseline homes than in MAP homes. Adjusting for the use of non-electric heat increased the estimated energy savings substantially, particularly in $\mathrm{CZ} 3$. Whether the relative lack of non-electric heating in MAP homes was a consequence of the program or not is unknown, but in this time period the effect of non-electric heat on electricity consumption significantly affected the difference between MAP and baseline home energy use.

Second, in CZ 1 heat pumps were more common in baseline homes and they tended to reduce energy consumption. Third, in all zones, energy consumption increased with increases in shell area and the effect was greater in the colder zones. Because baseline homes were smaller than MAP homes on the average, the shell area influence tended to reduce the observed difference between electricity use in MAP and baseline homes.

We examined the distribution of total electricity consumption and consumption per square foot in MAP and baseline homes to get a better understanding of the consumption patterns. Table 2.3 displays the distributions of raw $\mathrm{kWh} / \mathrm{ft}^{2}$ for the two 
samples in CZs 1 and 2. ${ }^{\text {(a) }}$ The values for the percentiles shown indicate that the distributions are narrower for the MAP homes than for the baseline homes. In CZ 2, for example, the difference between $\mathrm{kWh} / \mathrm{ft}^{2}$ at the 75th and 25th percentiles is 5.3 for baseline homes and 4.39 for MAP homes. The differences in CZ 1 are even larger. These results suggest that the energy demands faced by utilities may be more predictable and exhibit less variance for MAP homes than standard efficiency manufactured homes.

TABLE 2.3. Distributions of Raw Electricity Consumption

\begin{tabular}{||l|c|c|c|c||}
\hline \multirow{2}{*}{ Percentile } & \multicolumn{2}{|c|}{$\mathrm{CZ} 1, \mathrm{kWh} / \mathrm{ft}^{2}$} & \multicolumn{2}{c|}{$\mathrm{CZ} 2, \mathrm{kWh} / \mathrm{ft}^{2}$} \\
\cline { 2 - 5 } & $\begin{array}{c}\text { Baseline } \\
\text { homes }\end{array}$ & $\begin{array}{c}\text { MAP } \\
\text { homes }\end{array}$ & $\begin{array}{c}\text { Baseline } \\
\text { homes }\end{array}$ & $\begin{array}{c}\text { MAP } \\
\text { homes }\end{array}$ \\
\hline \hline 90th & 18.3 & 12.6 & 18.4 & 17.1. \\
\hline 75th & 14.5 & 11.7 & 16.1 & 13.9 \\
\hline 50th & 11.8 & 9.95 & 13.8 & 11.5 \\
\hline 25th & 9.51 & 8.05 & 10.8 & 9.51 \\
\hline 10th & 7.55 & 6.25 & 8.44 & 8.01 \\
\hline \hline
\end{tabular}

This first-tier analysis was limited to annual billing data and made no attempt to examine space conditioning and other temperature-sensitive end uses. No

- adjustments were made to normalize the effect of weather. The next chapter begins to address these factors.

(a) There are to o few observations in $\mathrm{CZ} 3$ to calculate meaningful percentiles. 


\subsection{SECOND-TIER ANALYSIS: PRISM ANALYSIS}

This section provides details on all of the results generated as part of the PRISM analysis. We acknowledge the assistance provided by Margaret Fels, Princeton University, and her team in making a pre-release copy of the advanced PRISM model available for this study.

\subsection{UNFILTERED PRISM ANALYSIS OF BILLING DATA}

In this subsection, the PRISM results are presented for all homes that could be analyzed, without making any judgments about whether or not the model fit the billing data well. The unfiltered analysis includes homes that have non-electric heat, a PRISM-estimated negative base load, and other homes that may have been poorly modeled by PRISM, with the exception of homes that failed to converge on a heating temperature. We started by examining the energy usage components for the entire sample. As a second step, we broke the sample down into MAP and baseline homes. Third, we segmented these components into heating-only $(\mathrm{HO})$ and heating and cooling $(\mathrm{IHC})$ model categories to differentiate those homes that had statistically significant air conditioning loads from those homes that had no significant air conditioning load. Finally, we present the results categorized by climate zone.

\subsubsection{Calculation of Standard Errors}

In all of the tables in this chapter, we present both annual energy usage and the corresponding standard errors of the energy usage in units of kilowatt-hours. The PRISM model produces standard errors for the heating, cooling, and total Normalized Annual Consumption (NAC) estimates for every customer. To calculate the standard error (SE) of the base load estimate for a single customer, we used the standard propagation of error technique of taking the square root of the sum of the squares of the standard errors for the heating, cooling and total NACs, as can be seen in Equation (3.1).

$$
S E_{\text {baseload }}=\sqrt{\left(S E_{\text {heat }}\right)^{2}+\left(S E_{\text {cool }}\right)^{2}+\left(S E_{\text {total }}\right)^{2}}
$$

However, the tables in this section present the standard error of the mean heating, cooling, base load and total estimates for groups of homes. To calculate the standard errors of the mean energy usage for a given end use across homes, Equation (3.2) was used. 


$$
S E_{\text {ond-use }}=\left(\frac{1}{n}\right) \sqrt{\sum_{l=1}^{n}\left(S E_{\text {ond-use, },}\right)^{2}}
$$

where $S E_{\text {end-use, } i}$ is the standard error for either the heating, cooling, total or base load energy component for the ith home from PRISM and $n$ is the number of homes.

\subsubsection{Energy Use for Both Samples Combined, Unfiltered}

For the initial PRISM analysis, we analyzed the sample of 256 MAP and baseline homes combined. The base loads were estimated by subtracting the normalized annual "heating" and cooling energy consumption from the normalized annual total consumption, which are both obtained from the PRISM results. ${ }^{(a)}$. The results of these analyses are shown in Table 3.1.

TABLE 3.1. PRISM Results for Entire Study Sample, Unfiltered

\begin{tabular}{|c|c|c|c|}
\hline & Energy Component & $\begin{array}{c}\text { Mean Energy Use } \\
\text { (kWh) }\end{array}$ & $\begin{array}{l}\text { Standard Error } \\
\text { (kWh) }\end{array}$ \\
\hline "Hea & 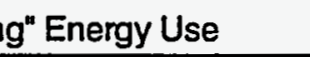 & 8,801 & 8,425 \\
\hline Coo & g Energy Use & 110 & 216 \\
\hline Bas & oad Energy Use ${ }^{(a)}$ & 9,098 & 8,686 \\
\hline Tota & nergy Use & 18,019 & 999 \\
\hline Sam & Size & \multicolumn{2}{|c|}{256} \\
\hline (a) & \multicolumn{3}{|c|}{$\begin{array}{l}\text { PRISM does not calculate the normalized base load; it was generated by } \\
\text { subtracting the normalized annual "heating" and cooling energy use from } \\
\text { the normalized annual total energy use. }\end{array}$} \\
\hline
\end{tabular}

These results indicate that the average base load energy use across all homes in our samples was about $9,000 \mathrm{kWh}$ per year. Because the homes in the samples varied and

(a) The PRISM "heating" consumption estimates are more properly considered to be the consumption component that is sensitive to heating-degree days. We report our estimates as "heating" consumption estimates, but the reader should be aware that this PRISM output can capture other temperature-sensitive electricity consumption for end-uses such as water heating and lighting. 
the data were not filtered, the standard error of the "heating" estimated mean was large ( $96 \%$ of the mean value).

\subsubsection{MAP and Baseline Home Energy Use, Unfiltered}

As a second step, we compared the energy use estimates for the MAP and baseline home samples; for this analysis we had 139 MAP and 117 baseline homes. As with all the "unfiltered" analyses, we removed no homes from the analysis. These results are presented in Table 3.2.

TABLE 3.2. MAP and Baseline Home Energy Use Comparison, Unfiltered

\begin{tabular}{|c|c|c|c|c|}
\hline \multirow[b]{2}{*}{ Energy Component } & \multicolumn{2}{|c|}{ Baseline Homes } & \multicolumn{2}{|c|}{ MAP Homes } \\
\hline & $\begin{array}{c}\text { Mean Energy } \\
\text { Use (kWh) }\end{array}$ & $\begin{array}{l}\text { Standard Error } \\
(\mathrm{kWh})\end{array}$ & $\begin{array}{c}\text { Mean Energy } \\
\text { Use (kWh) }\end{array}$ & $\begin{array}{l}\text { Standard Error } \\
(\mathrm{kWh})\end{array}$ \\
\hline "Heating" Energy Use & 9,737 & 1,298 & 8,014 & 4,082 \\
\hline Cool Energy Use & 130 & 95 & 94 & 53 \\
\hline Base Load Energy Use & 9,190 & 306 & 9,020 & 4,083 \\
\hline Total Energy Use & 19,057 & 117 & 17,128 & 105 \\
\hline Sample Size & \multicolumn{2}{|c|}{117} & \multicolumn{2}{|c|}{139} \\
\hline
\end{tabular}

The base load energy use of both MAP and baseline homes was around 9,000 $\mathrm{kWh} /$ year. The mean "heating" energy use of MAP homes was about $1,700 \mathrm{kWh} /$ year less than the baseline homes, while the total energy use was about $2,000 \mathrm{kWh} /$ year less for MAP homes. The standard error of the MAP "heating" use was about half the value of the mean.

\subsubsection{Usage Disaggregated by PRISM Model, Unfiltered}

In the third step; we disaggregated unfiltered results for both samples into PRISM model categories depending upon whether they were produced by the $\mathrm{HO}$ or $\mathrm{IHC}$ models. Table 3.3 presents these results. 
TABLE 3.3. Energy Use Comparison by PRISM Model, Unfiltered

\begin{tabular}{|c|c|c|c|c|c|}
\hline \multirow[b]{2}{*}{ PRISM Model } & \multirow[b]{2}{*}{ Energy Component } & \multicolumn{2}{|c|}{ Baseline Homies } & \multicolumn{2}{|c|}{ MAP Homes } \\
\hline & & $\begin{array}{c}\text { Mean } \\
\text { Energy Use } \\
(\mathrm{kWh})\end{array}$ & $\begin{array}{c}\text { Standard } \\
\text { Error } \\
(\mathrm{kWh})\end{array}$ & $\begin{array}{c}\text { Mean } \\
\text { Energy Use } \\
\text { (kWh) }\end{array}$ & $\begin{array}{c}\text { Standard } \\
\text { Error } \\
\text { (kWh) }\end{array}$ \\
\hline \multirow{4}{*}{$\mathrm{HO}$} & "Heating" Energy Use & 9,798 & 1,458 & 8,024 & 4,531 \\
\hline & Base Load Energy Use & 9,399 & 1,464 & 9,016 & 4,532 \\
\hline & Total Energy Use & 19,197 & 128 & 17,041 & 110 \\
\hline & Sample Size & \multicolumn{2}{|c|}{101} & \multicolumn{2}{|c|}{125} \\
\hline \multirow{5}{*}{ IHC } & "Heating" Energy Use & 9,353 & 2,302 & 7,919 & 2,455 \\
\hline & Cooling Energy Use & 953 & 698 & 931 & 523 \\
\hline & Base Load Energy Use & 7,868 & 2,420 & 9,058 & 2,536 \\
\hline & Total Energy Use & 18,173 & 264 & 17,908 & 359 \\
\hline & Sample Size & \multicolumn{2}{|c|}{16} & \multicolumn{2}{|c|}{14} \\
\hline
\end{tabular}

The results in Table 3.3 show that the estimated base load energy use of baseline homes differed considerably, about $1,500 \mathrm{kWh} /$ year, between homes modeled with the $\mathrm{HO}$ and IHC model. This result might indicate discrepancies in the models or arise from the small IHC analysis sample size. Using the HO model, MAP home "heating" energy use was about $1,700 \mathrm{kWh} /$ year less than for baseline homes and total energy use was about $2,100 \mathrm{kWh} /$ year less. Using the IHC model, "heating" energy use was about 1,400 and total energy use was only about $300 \mathrm{kWh} /$ year less for MAP homes. The largest standard errors were associated with "heating" energy estimates for MAP homes.

\subsubsection{Energy Use Estimates by Climate Zone, Unfiltered}

As a next step in the analysis, the results were categorized by climate zone. Tables $3.4 a$, $b$, and $c$ present the energy use components by PRISM model and climate zone. Comparing the results across climate zones, the largest standard errors were associated with MAP homes in CZ 1. In general, there were too few observations analyzed with the IHC model to draw reliable conclusions, and there were too few observations in $\mathrm{CZ} 3$ to produce reliable results. The results for $C Z 1$ suggested that MAP homes used about $2,100 \mathrm{kWh} /$ year less total energy than baseline homes, and the "heating" estimates showed that MAP homes used about 2,300 kWh/year less than baseline homes. 
TABLE 3.4a. Energy Use Comparison for CZ1, Unfiltered

\begin{tabular}{|c|c|c|c|c|c|}
\hline \multirow[b]{2}{*}{$\begin{array}{l}\text { PRISM } \\
\text { Model }\end{array}$} & \multirow[b]{2}{*}{ Energy Component } & \multicolumn{2}{|c|}{ Baseline Homes } & \multicolumn{2}{|c|}{ MAP Homes } \\
\hline & & $\begin{array}{l}\text { Mean Energy } \\
\text { Use (kWh) }\end{array}$ & $\begin{array}{c}\text { Standard } \\
\text { Error } \\
(\mathrm{kWh})\end{array}$ & $\begin{array}{c}\text { Mean Energy } \\
\text { Use } \\
\text { (kWh) }\end{array}$ & $\begin{array}{c}\text { Standard } \\
\text { Error } \\
(k W h)\end{array}$ \\
\hline \multirow[t]{4}{*}{ HO } & "Heating" Energy Use & 9,710 & 1,600 & 7,417 & 9,372 \\
\hline & Base Load Energy Use & 9,004 & 1,609 & 8,193 & 9,373 \\
\hline & Total Energy Use & 18,714 & 165 & 15,611 & 160 \\
\hline & Sample Size & \multicolumn{2}{|c|}{63} & \multicolumn{2}{|c|}{59} \\
\hline \multirow[t]{5}{*}{ IHC } & "Heating" Energy Use & 8,622 & 2,465 & 6,664 & 4,611 \\
\hline & Cooling Energy Use & 675 & 759 & 799 & 777 \\
\hline & Base Load Energy Use & 8,120 & 2,597 & 8,762 & 4,689 \\
\hline & Total Energy Use & 17,417 & 301 & 16,225 & 340 \\
\hline & Sample Size & \multicolumn{2}{|c|}{12} & \multicolumn{2}{|c|}{7} \\
\hline
\end{tabular}

TABLE 3.4b. Energy Use Comparison for CZ 2, Unfiltered

\begin{tabular}{|c|c|c|c|c|c|}
\hline \multirow[b]{2}{*}{$\begin{array}{l}\text { PRISM } \\
\text { Model }\end{array}$} & \multirow[b]{2}{*}{ Energy Component } & \multicolumn{2}{|c|}{ Baseline Homes } & \multicolumn{2}{|c|}{ MAP Homes } \\
\hline & & $\begin{array}{l}\text { Mean Energy } \\
\text { Use (kWh) }\end{array}$ & $\begin{array}{c}\text { Standard } \\
\text { Error } \\
\text { (kWh) }\end{array}$ & $\begin{array}{c}\text { Mean Energy } \\
\text { Use } \\
(\mathrm{kWh})\end{array}$ & $\begin{array}{c}\text { Standard } \\
\text { Error } \\
(\mathrm{kWh}) \\
\end{array}$ \\
\hline \multirow[t]{4}{*}{$\mathrm{HO}$} & "Heating" Energy Use & 9,789 & 3,350 & 8,159 & 2,524 \\
\hline & Base Load Energy Use & 10,214 & 3,358 & 9,805 & 2,531 \\
\hline & Total Energy Use & 20,003 & 231 & 17,965 & 187 \\
\hline & Sample Size & \multicolumn{2}{|c|}{32} & \multicolumn{2}{|c|}{48} \\
\hline \multirow[t]{5}{*}{ IHC } & "Heating" Energy Use & 11,544 & 5,484 & 9,384 & 1,842 \\
\hline & Cooling Energy Use & 1,787 & 1,614 & 881 & 566 \\
\hline & Base Load Energy Use & 7,111 & 5,743 & 8,173 & 1,975 \\
\hline & Total Energy Use & 20,442 & 547 & 18,439 & 433 \\
\hline & Sample Size & \multicolumn{2}{|c|}{4} & \multicolumn{2}{|c|}{5} \\
\hline
\end{tabular}


TABLE 3.4c. Energy Use Comparison for CZ 3, Unfiltered

\begin{tabular}{|c|c|c|c|c|c|}
\hline \multirow[b]{2}{*}{$\begin{array}{l}\text { PRISM } \\
\text { Model }\end{array}$} & \multirow[b]{2}{*}{ Energy Component } & \multicolumn{2}{|c|}{ Baseline Homes } & \multicolumn{2}{|c|}{ MAP Homes } \\
\hline & & $\begin{array}{c}\text { Mean Energy } \\
\text { Use (kWh) }\end{array}$ & $\begin{array}{l}\text { Standard } \\
\text { Error } \\
(\mathrm{kWh})\end{array}$ & $\begin{array}{c}\text { Mean Energy } \\
\text { Use } \\
\text { (kWh) }\end{array}$ & $\begin{array}{c}\text { Standard } \\
\text { Error } \\
(\mathrm{kWh})\end{array}$ \\
\hline \multirow[t]{4}{*}{ HO } & "Heating" Energy Use & 10,771 & 1,082 & 9,652 & 912 \\
\hline & Base Load Energy Use & 9,198 & 1,150 & 9,611 & 942 \\
\hline & Total Energy Use & 19,969 & 390 & 19,262 & 235 \\
\hline & Sample Size & \multicolumn{2}{|c|}{6} & \multicolumn{2}{|c|}{18} \\
\hline \multirow[t]{5}{*}{$\mathrm{IHC}$} & "Heating" Energy Use & -- & - & 8,646 & 1,855 \\
\hline & Cooling Energy Use & - & - & 1,521 & 1,002 \\
\hline & Base Load Energy Use & - & - & 12,304 & 2,318 \\
\hline & Total Energy Use & - & - & 22,471 & 963 \\
\hline & Sample Size & \multicolumn{2}{|c|}{0} & \multicolumn{2}{|c|}{2} \\
\hline
\end{tabular}

\subsection{PRISM ANALYSIS OF STAGE-ONE FILTERED SAMPLE}

For this stage of the analysis, we examined the unfiltered PRISM results for the billing data and excluded those homes that met the following criteria:

- Non-converging heating temperatures in PRISM

- $\quad \mathrm{R}^{2}$ less than 0.65

- $\quad$ PRISM produced a zero heating load

- Survey indicated more than $10 \%$ of the heating was provided by a non-electric fuel source

- $\quad$ PRISM models indicated a negative base load.

In this report, we are referring to this level of filtered data as "stage-one" filtering. The PRISM developers have indicated that they would exclude homes that have an $R^{2}$ less than 0.70 (Fels, Reynolds, and Stram 1986); however, we would have had to exclude another seven observations from our study if we had chosen to use the same cutoff 
level. Due to our relatively small sample sizes, we chose to use an $R^{2}$ of 0.65 as the cutoff level. We then proceeded with the steps discussed in Section 3.1.

\subsubsection{Energy Use for Both Samples Combined, Stage-One Filtered}

Using the screening criteria, we excluded 64 sites and were left with a total sample of 192 sites. Results for the remaining sites are described in Table 3.5.

TABLE 3.5. PRISM Results for Entire Study Sample, Stage-One Filtered

\begin{tabular}{||l|c|c|}
\hline \multicolumn{1}{|c|}{ Energy Component } & $\begin{array}{c}\text { Mean Energy Use } \\
(\mathrm{kWh})\end{array}$ & $\begin{array}{c}\text { Standard Error } \\
(\mathrm{kWh})\end{array}$ \\
\hline \hline "Heating" Energy Use & 9,377 & 393 \\
\hline Cooling Energy Use & 107 & 59 \\
\hline Base Load Energy Use & 9,136 & 404 \\
\hline Total Energy Use & 18,619 & 74 \\
\hline Sample Size & & 192 \\
\hline
\end{tabular}

The major impact of screening out the observations that PRISM did not model well was a significant reduction in the standard errors. Both the estimated "heating" and total energy use increased by about $600 \mathrm{kWh} /$ year, compared with Table 3.1.

\subsubsection{MAP and Baseline Home Energy Use, Stage-One Filtered}

In the second step, we examined differences in energy use between the MAP and baseline home samples; for this analysis we had 108 MAP homes and 84 baseline homes remaining from our original samples as can be seen in Table 3.6.

Again, the major difference between these results and the unfiltered results (Table 3.3) was a significant reduction in the standard errors. The base load energy use estimated for both MAP and baseline homes was around $9,000 \mathrm{kWh} /$ year. The difference between MAP and baseline home "heating" and total energy use was about 1,500 kWh/year. 
TABLE 3.6. MAP and Baseline Home Energy Use Comparison, Stage-One Filtered

\begin{tabular}{||l|c|c|c|c||}
\hline \multirow{2}{*}{ Energy Component } & \multicolumn{2}{|c|}{ Baseline Homes } & \multicolumn{2}{c|}{ MAP Homes } \\
\cline { 2 - 6 } & $\begin{array}{c}\text { Mean Energy } \\
\text { Use (kWh) }\end{array}$ & $\begin{array}{c}\text { Standard Error } \\
(\mathrm{kWh})\end{array}$ & $\begin{array}{c}\text { Mean Energy } \\
\text { Use (kWh) }\end{array}$ & $\begin{array}{c}\text { Standard Error } \\
(\mathrm{kWh})\end{array}$ \\
\hline \hline "Heating" Energy Use & 10,232 & 598 & 8,712 & 521 \\
\hline Cooling Energy Use & 112 & 113 & 102 & 57 \\
\hline Base Load Energy Use & 9,085 & 617 & 9,175 & 538 \\
\hline Total Energy Use & 19,429 & 102 & 17,990 & 104 \\
\hline Sample Size & \multicolumn{2}{|c|}{84} & \multicolumn{2}{c|}{108} \\
\hline
\end{tabular}

\subsubsection{Usage Disaggregated by PRISM Model, Stage-One Filtered}

Next, the PRISM results were further broken down by PRISM model (HO or IHC) as seen in Table 3.7. Compared with Table 3.3, the major change for HO-modeled homes was a significant reduction in the standard errors. The base load energy use estimates for MAP and baseline homes were closer than in the results without screening out the poor PRISM fits. The differences between MAP and baseline homes total energy use were about $1,400 \mathrm{kWh} /$ year using both models.

\subsubsection{Energy Use Estimates by Climate Zone, Stage-One Filtered}

As a final step in the stage-one filtering analysis, the results were categorized by climate zone. Table 3.8 shows, again, that standard errors were reduced from the unfiltered analysis, particularly for the $\mathrm{HO}$ model results and especially in $\mathrm{CZ} 1$. These results suggested that several CZ 1 MAP homes had unusual characteristics that affected their energy consumption significantly. The base load estimates tended to vary less between MAP and baseline homes, but showed a tendency to increase in the colder climate zones. The results indicated that "heating" energy use in MAP homes was less than in baseline homes. In general, the results for $\mathrm{CZ} 3$ and for homes modeled with the IHC model were not very reliable because of small sample sizes.

\subsubsection{Energy Savings Estimates by Climate Zone, Stage-One Filtered}

Table 3.9 presents estimated energy savings based on our stage-one filtered PRISM results. The savings are shown as normalized annual energy consumption by climate zone and PRISM model for the filtered analysis. 
TABLE 3.7. Energy Use Comparison by PRISM Model, Stage-One Filtered

\begin{tabular}{|c|c|c|c|c|c|}
\hline \multirow[b]{2}{*}{$\begin{array}{l}\text { PRISM } \\
\text { Model }\end{array}$} & \multirow[b]{2}{*}{ Energy Component } & \multicolumn{2}{|c|}{ Baseline Homes } & \multicolumn{2}{|c|}{ MAP Homes } \\
\hline & & $\begin{array}{c}\text { Mean Energy } \\
\text { Use (kWh) }\end{array}$ & $\begin{array}{c}\text { Standard } \\
\text { Error } \\
\text { (kWh) }\end{array}$ & $\begin{array}{l}\text { Mean Energy } \\
\text { Use (kWh) }\end{array}$ & $\begin{array}{c}\text { Standard } \\
\text { Error } \\
\text { (kWh) }\end{array}$ \\
\hline \multirow[t]{4}{*}{ HO } & "Heating" Energy Use & 10,227 & 578 & 8,752 & 476 \\
\hline & Base Load Energy Use & 9,215 & 588 & 9,249 & 488 \\
\hline & Total Energy Use & 19,442 & 107 & 18,001 & 110 \\
\hline & Sample Size & \multicolumn{2}{|c|}{72} & \multicolumn{2}{|c|}{96} \\
\hline \multirow{5}{*}{$\mathrm{IHC}$} & "Heating" Energy Use & 10,263 & 2,336 & 8,396 & 2,738 \\
\hline & Cooling Energy Use & 783 & 789 & 921 & 515 \\
\hline & Base Load Energy Use & 8,306 & 2,484 & 8,585 & 806 \\
\hline & Total Energy Use & 19,352 & 309 & 17,902 & 332 \\
\hline & Sample Size & \multicolumn{2}{|c|}{12} & \multicolumn{2}{|c|}{12} \\
\hline
\end{tabular}

TABLE 3.8a. Energy Use Comparison for CZ 1, Stage-One Filtered

\begin{tabular}{|c|c|c|c|c|c|}
\hline \multirow[b]{2}{*}{$\begin{array}{l}\text { PRISM } \\
\text { Model }\end{array}$} & \multirow[b]{2}{*}{ Energy Component } & \multicolumn{2}{|c|}{ Baseline Homes } & \multicolumn{2}{|c|}{ MAP Homes } \\
\hline & & $\begin{array}{l}\text { Mean Energy } \\
\text { Use (kWh) }\end{array}$ & $\begin{array}{c}\text { Standard } \\
\text { Error } \\
(\mathrm{kWh})\end{array}$ & $\begin{array}{c}\text { Mean Energy } \\
\text { Use } \\
\text { (kWh) }\end{array}$ & $\begin{array}{c}\text { Standard } \\
\text { Error } \\
(\mathrm{kWh})\end{array}$ \\
\hline \multirow[t]{4}{*}{$\mathrm{HO}$} & "Heating" Energy Use & 9,534 & 802 & 7,833 & 752 \\
\hline & Base Load Energy Use & 8,560 & 811 & 8,746 & 771 \\
\hline & Total Energy Use & 18,094 & 124 & 16,579 & 168 \\
\hline & Sample Size & \multicolumn{2}{|c|}{49} & \multicolumn{2}{|c|}{44} \\
\hline \multirow[t]{5}{*}{ IHC } & "Heating" Energy Use & 9,246 & 2,636 & 7,285 & 5,207 \\
\hline & Cooling Energy Use & 675 & 859 & 815. & 838 \\
\hline & Base Load Energy Use & 8,181 & 2,794 & 8,852 & 5,287 \\
\hline & Total Energy Use & 18,102 & 344 & 16,952 & 371 \\
\hline & Sample Size & \multicolumn{2}{|c|}{10} & \multicolumn{2}{|c|}{6} \\
\hline
\end{tabular}


TABLE 3.8b. Energy Use Comparison for CZ2, Stage-One Filtered

\begin{tabular}{||c|l|c|c|c|c||}
\hline \multirow{4}{*}{$\begin{array}{c}\text { PRISM } \\
\text { Model }\end{array}$} & \multicolumn{2}{|c|}{ Baseline Homes } & \multicolumn{2}{c|}{ MAP Homes } \\
\cline { 3 - 7 } & Energy Component & $\begin{array}{c}\text { Mean Energy } \\
\text { Use (kWh) }\end{array}$ & $\begin{array}{c}\text { Standard } \\
\text { Error } \\
(\mathrm{kWh})\end{array}$ & $\begin{array}{c}\text { Mean Energy } \\
\text { Use } \\
(\mathrm{kWh})\end{array}$ & $\begin{array}{c}\text { Standard } \\
\text { Error } \\
(\mathrm{kWh})\end{array}$ \\
\hline \hline \multirow{3}{*}{ HO } & "Heating" Energy Use & 11,324 & 666 & 9,249 & 760 \\
\cline { 2 - 7 } & Base Load Energy Use & 10,808 & 703 & 9,786 & 780 \\
\cline { 2 - 7 } & Total Energy Use & 22,132 & 225 & 19,080 & 176 \\
\cline { 2 - 7 } & Sample Size & & 19 & & 37 \\
\hline \hline \multirow{3}{*}{ IHC } & "Heating" Energy Use & 15,346 & 4,764 & 9,384 & 1,842 \\
\cline { 2 - 7 } & Cooling Energy Use & 1,328 & 2,000 & 881 & 566 \\
\cline { 2 - 7 } & Base Load Energy Use & 8,929 & 5,214 & 8,173 & 1,975 \\
\cline { 2 - 7 } & Total Energy Use & 25,603 & 698 & 18,439 & 433 \\
\cline { 2 - 7 } & Sample Size & & 2 & & 5 \\
\hline
\end{tabular}

TABLE 3.8c. Energy Use Comparison for CZ 3, Stage-One Filtered

\begin{tabular}{|c|c|c|c|c|c|}
\hline \multirow[b]{2}{*}{$\begin{array}{l}\text { PRISM } \\
\text { Model }\end{array}$} & \multirow[b]{2}{*}{ Energy Component } & \multicolumn{2}{|c|}{ Baseline Homes } & \multicolumn{2}{|c|}{ MAP Homes } \\
\hline & & $\begin{array}{c}\text { Mean Energy } \\
\text { Use (kWh) }\end{array}$ & $\begin{array}{c}\text { Standard } \\
\text { Error } \\
(\mathrm{kWh}) \\
\end{array}$ & $\begin{array}{c}\text { Mean Energy } \\
\text { Use } \\
(\mathrm{kWh})\end{array}$ & $\begin{array}{c}\text { Standard } \\
\text { Error } \\
\text { (kWh) } \\
\end{array}$ \\
\hline \multirow[t]{4}{*}{ HO } & "Heating" Energy Use & 13,502 & 1,377 & 10,111 & 942 \\
\hline & Base Load Energy Use & 9,666 & 1,464 & 9,397 & 974 \\
\hline & Total Energy Use & 23,168 & 498 & 19,508 & 245 \\
\hline & Sample Size & \multicolumn{2}{|c|}{4} & \multicolumn{2}{|c|}{15} \\
\hline \multirow[t]{5}{*}{$\mathrm{IHC}$} & "Heating" Energy Use & - & - & 10,119 & 4,312 \\
\hline & Cooling Energy Use & - & - & 1,756 & 2,200 \\
\hline & Base Load Energy Use & - & - & 9,046 & 5,443 \\
\hline & Total Energy Use & - & - & 20,921 & 2,490 \\
\hline & Sample Size & \multicolumn{2}{|c|}{0} & \multicolumn{2}{|c|}{1} \\
\hline
\end{tabular}


TABLE 3.9. "Heating" Energy Savings. for Stage-One Filtered Analysis

\begin{tabular}{|c|c|c|c||}
\hline PRISM Model & $\mathrm{CZ}$ & $\begin{array}{c}\text { Annual Energy } \\
\text { Savings } \\
(\mathrm{kWh})\end{array}$ & $\begin{array}{c}\text { Standard Error } \\
(\mathrm{kWh})\end{array}$ \\
\hline \hline \multirow{3}{*}{$\mathrm{HO}$} & 1 & 1,701 & 1,099 \\
\cline { 2 - 4 } & 2 & 2,075 & 1,010 \\
\cline { 2 - 4 } & 3 & 3,391 & 1,668 \\
\hline \hline \multirow{3}{*}{ IHC } & 1 & 1,961 & 5,836 \\
\cline { 2 - 5 } & 2 & 5,962 & 5,108 \\
\cline { 2 - 5 } & 3 & - & - \\
\hline \multirow{2}{*}{$\cdot-$-' Indicates that no data are available } & & \\
\hline
\end{tabular}

The savings estimates in Table 3.9 are based on differences in the "heating" energy . estimates. The savings are larger for the colder climate zones, as would be expected. For the HO-modeled homes, the standard error is about half the mean savings estimate: The IHC-modeled results cannot be considered reliable because of the small sample sizes.

\subsection{PRISM ANALYSIS OF STAGE-TWO FILTERED SAMPLE}

For the next stage of the analysis, we further filtered the sample to remove homes that had an air-conditioning load or used any non-electric heating. Stage two includes the conditions imposed upon the stage-one analysis plus the addition of two more criteria: 1) use of a non-electric heat source for any portion of the heating load and 2) a PRISM air-conditioning NAC greater than zero. The screening criteria that we used were the following:

- Non-converging heating temperatures in PRISM

- $\mathrm{R}^{2}$ less than 0.65

- $\quad$ PRISM produced a zero heating load

- Any non-electric heating fuel use (based on survey responses) 
- $\quad$ PRISM models indicated a negative base load

- A PRISM air-conditioning load greater than zero

We refer to this level of filtered data as stage-two filtering. This filtering should remove any distortions in the PRISM results due to use of non-electric heat. Because the IHC results were based on such small sample sizes and the air-conditioning loads were relatively small, elimination of homes with air-conditioning loads should improve the reliability of the estimates.

\subsubsection{Energy Use for Both Samples Combined, Stage-Two Filtered}

Using the criteria presented in Section 3.3, we excluded 118 sites and were left with a total sample of 138 sites. Results for the remaining sites are presented in Table 3.10. These results did not differ significantly from the aggregate results presented for stageone filtering in Table 3.5. Compared with results for the unfiltered sample, the standard errors were significantly less; they were similar to those from stage-one filtering.

TABLE 3.10. PRISM Results for Entire Study Sample, Stage-Two Filtered

\begin{tabular}{||l|c|c|}
\hline \hline \multicolumn{1}{|c|}{ Energy Component } & $\begin{array}{c}\text { Mean Energy Use } \\
(\mathrm{kWh})\end{array}$ & $\begin{array}{c}\text { Standard Error } \\
(\mathrm{kWh})\end{array}$ \\
\hline \hline "Heating" Energy Use & 9,452 & 430 \\
\hline Base Load Energy Use & 8,929 & 439 \\
\hline Total Energy Use & 18,381 & 86 \\
\hline Sample Size & \multicolumn{2}{|c|}{138} \\
\hline
\end{tabular}

\subsubsection{MAP and Baseline Home Energy Use, Stage-Two Filtered}

As a second step, we compared the energy use of the MAP and baseline homes; for this analysis we had 78 MAP homes and 60 baseline homes remaining from our original samples as can be seen in Table 3.11. Again, the results did not differ significantly from those from the stage-one filtered analysis presented in Table 3.6. 


\subsubsection{Energy Use Estimates by Climate Zone, Stage-Two Filtered}

As a final step in the stage-two filtering analysis, the results were further categorized by climate zone as shown in Table 3.12. Comparing these results with those presented in Table 3.8, most load estimates were decreased as a result of additional filtering, although there were no substantial differences. The results suggested that the base load increased going from $\mathrm{CZ} 1$ to $\mathrm{CZ} 2$.

\subsubsection{Energy Savings Estimates by Climate Zone, Stage-Two Filtered}

Table 3.13 presents estimated energy savings based on our stage-two filtered PRISM estimates. The savings were calculated by taking the difference between the mean "heating" estimates for baseline and MAP homes, by climate zone. The estimated savings range from about $1,400 \mathrm{kWh} /$ year in $\mathrm{CZ} 1$ to $3,800 \mathrm{kWh} /$ year in $\mathrm{CZ} 3$. The standard errors range from $44 \%$ to $97 \%$ of the estimated mean savings.

\subsection{ADJUSTED PRISM RESULTS}

For this portion of the analysis, we examined the PRISM results that met the criteria previously presented for the stage-two analysis. We then investigated several methods

TABLE 3.11. MAP and Baseline Home Energy Use Comparison, Stage-Two Filtered

\begin{tabular}{||l|c|c|c|c||}
\hline \multirow{2}{*}{ Energy Component } & \multicolumn{2}{|c|}{ Baseline Homes } & \multicolumn{2}{c|}{ MAP Homes } \\
\cline { 2 - 5 } & $\begin{array}{c}\text { Mean Energy } \\
\text { Use (kWh) }\end{array}$ & $\begin{array}{c}\text { Standard Error } \\
(\mathrm{kWh})\end{array}$ & $\begin{array}{c}\text { Mean Energy } \\
\text { Use }(\mathrm{kWh})\end{array}$ & $\begin{array}{c}\text { Standard Error } \\
(\mathrm{kWh})\end{array}$ \\
\hline \hline "Heating" Energy Use & 10,293 & 671 & 8,804 & 559 \\
\hline Base Load Energy Use & 8,964 & 681 & 8,902 & 573 \\
\hline Total Energy Use & 19,257 & 115 & 17,707 & 124 \\
\hline Sample Size & \multicolumn{2}{|c|}{60} & & 78 \\
\hline
\end{tabular}


TABLE 3.12. Energy Use Comparison by Climate Zone, Stage-Two Filtered

\begin{tabular}{|c|c|c|c|c|c|}
\hline \multirow[b]{2}{*}{$\begin{array}{c}\text { Climate } \\
\text { Zone }\end{array}$} & \multirow[b]{2}{*}{ Energy Component } & \multicolumn{2}{|c|}{ Baseline Homes } & \multicolumn{2}{|c|}{ MAP Homes } \\
\hline & & $\begin{array}{c}\text { Mean Energy } \\
\text { Use (kWh) }\end{array}$ & $\begin{array}{c}\text { Standard } \\
\text { Error } \\
\text { (kWh) }\end{array}$ & $\begin{array}{c}\text { Mean.Energy } \\
\text { Use } \\
\text { (kWh) }\end{array}$ & $\begin{array}{c}\text { Standard } \\
\text { Error } \\
\text { (kWh) }\end{array}$ \\
\hline \multirow[t]{4}{*}{1} & "Heating" Energy Use & 9,617 & 981 & 8,190 & 969 \\
\hline & Base Load Energy Use & 8,519 & 991 & 8,008 & 990 \\
\hline & Total Energy Use & 18,136 & 142 & 16,198 & 204 \\
\hline & Sample Size & \multicolumn{2}{|c|}{39} & \multicolumn{2}{|c|}{34} \\
\hline \multirow[t]{4}{*}{2} & "Heating" Energy Use & 11,090 & 663 & 9,103 & 842 \\
\hline & Base Load Energy Use & 9,820 & 696 & 9,888 & 864 \\
\hline & Total Energy Use & 20,910 & 212 & 18,992 & 193 \\
\hline & Sample Size & \multicolumn{2}{|c|}{17} & \multicolumn{2}{|c|}{30} \\
\hline \multirow[t]{4}{*}{3} & "Heating" Energy Use & 13,502 & 1,377 & 9,656 & 961 \\
\hline & Base Load Energy Use & 9,666 & 1,464 & 8,961 & 992 \\
\hline & Total Energy Use & 23,168 & 498 & 18,617 & 245 \\
\hline & Sample Size & \multicolumn{2}{|c|}{4} & \multicolumn{2}{|c|}{14} \\
\hline
\end{tabular}

TABLE 3.13. "Heating" Energy Savings for Stage-Two Filtered Analysis

\begin{tabular}{|c|c|c|}
\hline Climate Zone & $\begin{array}{c}\text { Annual Energy Savings } \\
(\mathrm{kWh})\end{array}$ & $\begin{array}{c}\text { Standard Error } \\
(\mathrm{kWh})\end{array}$ \\
\hline \hline 1 & 1,427 & 1,379 \\
\hline 2 & 1,987 & 1,072 \\
\hline 3 & 3,846 & 1,679 \\
\hline
\end{tabular}

proposed in previous studies (including Roos and Baylon [1993], Hwang [1989], and others) for adjusting the PRISM estimates to compensate for known biases. This step builds on the data cleaning performed in stage two, by using an empirically derived equation to adjust the heating results to eliminate seasonal effects. After a thorough review of adjustment procedures, we further examined the only one that used both 
PRISM parameters and took into account the building thermal performance characteristics. The equation used to adjust the heating results is based upon a previous evaluation study performed by PNL for Bonneville and is presented below (Lee et al. 1988).

$$
H E A T_{\text {adf }}=(0.982)\left(\text { Heat }_{\text {PRISM }}\right)-(0.841)\left(H D D_{65}\right)+(61.8)(U A)-(0.85)\left(T_{\text {rof }}\right)(U A)
$$

where:

Heat $_{\mathrm{adj}}=$ adjusted heating value

Heat $_{\text {PRISM }}=$ PRISM estimated "heating" value

$\mathrm{HDD}_{65}=$ annual heating degree days to base $65^{\circ} \mathrm{F}$

$\cup A=$ envelope $U A$

$T_{\text {ref }}=$ PRISM estimated heating reference temperature

After the adjustment process was completed, we examined the results for accuracy and consistency. Our findings indicated that, while the adjustment process appeared to produce reasonable heating savings estimates, the results were inconsistent when examined across the climate zones. The applicability of the adjustment was questioned due to the following observations:

- The unadjusted heating estimates increased from $\mathrm{CZ} 1$ to $\mathrm{CZ} 3$, while the adjusted results showed heating energy decreasing in the colder climates.

- The unadjusted base load estimates ranged from approximately 8,000 to 9,900 $\mathrm{kWh}$ annually, while the adjusted base loads ranged from about 8,000 to 14,000 kWh annually.

Due to these discrepancies, we have chosen not to present the adjusted heating savings in this report. 
3.16 


\subsection{THIRD-TIER ANALYSIS: REGRESSION ANALYSIS}

This section discusses our third-tier analysis approach, a regression analysis that attempts to control for a wide range of possible energy consumption determinants. Our purpose is to compare the MAP and baseline sample homes by focusing on the known and intentional differences between the two samples. We seek to control for differences in occupant demographics, appliance inventories, home sizes, and occupant behavior between the two samples.

We note that some of these differences may be influenced by MAP and should be considered in a complete evaluation of the program's impact. However, this analysis focuses on differences in the thermal physics of the MAP and baseline homes; a thorough evaluation of the degree to which MAP has influenced home buyer preferences or otherwise influenced the manufactured housing market is beyond the scope of this study.

\subsection{OVERVIEW OF APPROACH}

This approach was applied to all sample homes for which we obtained any billing data. Billing-period (usually monthly) data were used. Because the number of bills available for the homes varied widely, we weighted the data such that each home received equal influence in the overall regression.

Our general approach is to develop a model of total electric consumption that utilizes available information about the home in concert with known or anticipated thermalphysical relationships. The anticipated thermal-physical relationships include these:

- heating load response to outdoor temperature: ${ }^{(a)}$ this effect is expected to be influenced by a homes thermal integrity (the primary effect of MAP), size, and configuration (e.g., number of sections).

- cooling load response to outdoor temperature

- water heating load response to outdoor temperature: many any other end uses interact with the water heating load (dishwashers, hot tubs, etc.).

(a) Both heating and cooling are also functions of other influences, notably solar heat gains. Unfortunately, lack of solar data from most homes' locationś prevents direct modeling of these effects. 
- $\quad$ seasonal variation of various miscellaneous loads (e.g., lighting is expected to increase when days are shorter)

- response of various loads to the number of occupants.

The data for the homes that are available from our survey and supplemental data sources include the following:

- heating- and cooling-degree days (HDD and CDD) by billing period

- home characteristics (floor area, window area, number of sections, whether the home is a MAP or baseline home, and component $U$-values for 'baseline homes)

- $\quad$ appliance inventories

- occupant demographics (such as income level, age, and education)

- occupant behavior (self-reported thermostat settings, non-electric heat usage, daytime occupancy, etc.)

- anticipated seasonal variations in certain end-use loads obtained from other metering studies.

\subsection{METHODOLOGY}

The model we use is similar to a conditional demand analysis (CDA) in that it utilizes appliance inventories to explain total $\mathrm{kWh}$ consumption, but is formulated around the anticipated thermal-physical relationships. Because differences in heating (and maybe cooling) performance are the primary anticipated effect of MAP, we focus on those terms in formulating the model. The general framework is as follows:

$$
k W h / \text { day }=\text { Intercept }+\sum_{i=1}^{k}\left(\alpha, \times V_{i}\right)+\beta \times U A \times \frac{H D D}{\text { day }} \times C
$$

Where the ${ }^{\prime} \alpha_{\mathrm{i}}$ are regression coefficients for various demographic, behavioral, and appliance inventory variables $\left(V_{i}\right)$ and the $\beta$ is a heating response regression coefficient. Note that the HDD term already includes known information about a home's envelope conductance (UA). In this sense, the model has the characteristic of a statisticallyadjusted engineering model, albeit with a very simple engineering model. The UA used 
in the regression is based on manufacturers' data on home components for the baseline homes and on knowledge of MAP requirements for the MAP homes. The UA includes infiltration effects estimated from an air exchange rate of 0.35 air changes per hour $(A C H)$ for all homes. The $\beta$ coefficient adjusts the anticipated HDD slope to match the data. Thus, if Equation (4.1) were to perfectly model the heating response, the expected value of the $\beta$ coefficient would be unity. Realistically, we expect $\beta$ to be less than 1.0, because most homes have lower balance temperatures than the 65 degrees used to calculate HDD. ${ }^{(a)}$ The constant, $C$, adjusts the units of the term to match those of the dépendent variable.

In practice, Equation (4.1) is too simple to give meaningful results. The $\alpha$ and $\beta$ terms must be expanded to accommodate the specifics of the study at hand. For example, we expect a home's response to HDD to be different if it has a heat pump rather than an electric furnace. Likewise, MAP ventilation requirements are likely to make those homes respond differently to the weather than similar baseline homes, but the exact ventilation contribution to the UA is not known. Therefore, we "nest" the UA x HDD term within categorical variables for MAP and heating system type. Further, the presence of nonelectric heating systems in a home can seriously modify the home's response (in terms of electricity consumption) to outdoor temperature. Depending on how such backup systems are used, the response may or may not fit the linear form of Equation (4.1). For example, if a backup system supplies all the heating requirement for a part of the home, the electric response may continue to be linear. If, on the other hand, the backup system intermittently replaces the electric heater, as is common for wood stoves, the electric response may have no discernible functional relationship to outdoor temperature.

One way of dealing with this uncertainty would be to eliminate homes with backup heating systems from the analysis sample. This kind of analysis can be valuable when seeking the pure "engineering" effect of MAP on home construction. But it precludes evaluating MAP's real effect on regional electric loads. Our approach is to nest the UAx HDD term within a categorical variable defining the heating system type, where the system type includes information about backup systems present. This approach gives a separate $\beta$ coefficient for each combination of system type (heat pump or electric resistance) and backup system (wood stove, other). Note that the coefficients for the backup systems do not quite bear the physical significance implied by Equation (4.1). The nested regression formulation is useful, nonetheless, because only the all-electric

(a) The balance temperature is the outdoor temperature at which the furnace must come on to maintain the temperature setpoint. 
homes influence the electric-resistance-only and heat-pump-only $\beta$ coefficients, but all homes influence the coefficients on the other (non-thermal) terms.

In interpreting the $\beta$ coefficients, it is important to note that Equation (4.1) may not accurately model a home that has substantial cooling loads intermixed with heating loads during some parts of the year. This problem is more common in heat-pump homes because the thermostat is more likely to provide for either heating or cooling without the occupants moving a mode switch.

Roughly speaking, the $V_{i}$ terms represent the non-weather-sensitive "base" consumption of the home. However, it is well known that many of these base end uses do respond to climate variations or vary seasonally. To control for these effects, we adjust the appliance inventory variables to account for their expected seasonal variations. We use data from the Bonneville Power Administration's Regional End-Use Metering Project (REMP) to supply these adjustments (Cahill, Ritland, and Lin-Kelly, 1992). Table 4.1 shows the anticipated monthly variation in various end use loads expressed as a fraction of the annual mean consumption.

The final form of the model is shown as Equation (4.2). The terms in the equation are defined in Table 4.2. Note that the UA*HDD slope adjustments are obtained for MAP homes by regressing for a differential effect, rather than simply by partitioning the data into two subgroups (baseline and MAP). Thus the t-statistics of those coefficients better test the hypothesis that the MAP effect is non-zero. The terms that begin "Is" or "Has" are to be interpreted as binary (dummy) variables with a value of 1 if the implied assertion is true, 0 otherwise. IncomeLow and IncomeHigh are interpreted similarly, where income levels are designated as Low, Medium, or High, with Medium defined as between $\$ 25,000$ and $\$ 40,000$ annually.

\subsection{SUMMARY OF IMPLIED MAP SAVINGS}

Table 4.3 shows the estimated regression coefficients, obtained by subjecting Equation (4.2) to an ordinary least-squares (OLS) regression followed by a one-iteration transformed regression to adjust for serial correlation. The R-square value for the regression is 0.60 . The residual standard error of the regression is 10.9 on 2,722 degrees of freedom. Section 4.5 discusses specific econometric issues and goodnessof-fit indicators. Section 4.6 discusses the estimation of confidence intervals associated with this model. 
TABLE 4.1. Monthly Load Allocation Factors

\begin{tabular}{||c|c|c|c|c|c|c||}
\hline Month & $\begin{array}{c}\text { Water } \\
\text { Heater }\end{array}$ & $\begin{array}{c}\text { Refri- } \\
\text { gerator }\end{array}$ & Freezer & $\begin{array}{c}\text { Dish- } \\
\text { washer }\end{array}$ & Misc & $\begin{array}{c}\text { Wash/ } \\
\text { Dryer" }\end{array}$ \\
\hline \hline Jan & 1.127 & 0.990 & 0.811 & 1.078 & 1.122 & 1.060 \\
\hline Feb & 1.123 & 0.930 & 0.831 & 1.039 & 1.061 & 1.044 \\
\hline Mar & 1.092 & 0.937 & 0.885 & 1.023 & 0.991 & 1.041 \\
\hline Apr & 1.053 & 0.955 & 0.953 & 0.964 & 0.922 & 0.991 \\
\hline May & 1.006 & 0.997 & 1.028 & 0.939 & 0.910 & 0.971 \\
\hline Jun & 0.939 & 1.067 & 1.150 & 0.945 & 0.915 & 0.954 \\
\hline Jul & 0.878 & 1.115 & 1.186 & 0.932 & 0.925 & 0.933 \\
\hline Aug & 0.857 & 1.123 & 1.202 & 0.911 & 0.937 & 0.929 \\
\hline Sep & 0.905 & 1.046 & 1.112 & 1.002 & 0.943 & 0.962 \\
\hline Oct & 0.932 & 0.970 & 0.986 & 0.972 & 0.977 & 0.991 \\
\hline Nov & 1.003 & 0.944 & 0.873 & 1.065 & 1.072 & 1.020 \\
\hline Dec & 1.084 & 0.925 & 0.983 & 1.131 & 1.227 & 1.105 \\
\hline
\end{tabular}

(1) Computed as the average of washer and dryer allocations from Cahill, Ritland, and Lin-Kelly, 1992. 


$$
\begin{aligned}
& \frac{k W h}{N_{\text {days }}}=\text { Intercept } \\
& +\alpha_{1} \text { Incomelow } \\
& +\alpha_{2} \text { IncomeHigh } \\
& +\alpha_{3} \text { lsOccDaytime } \\
& +\alpha_{4} N_{\text {waterbods }} \\
& +\alpha_{5} N_{\text {computers }} \\
& +\alpha_{6} N_{\text {refrigerators }} \times A \text { Allo } C_{\text {refigerator }} \\
& +\alpha_{7} N_{\text {froozers }} \times A l l o c_{\text {froozer }} \\
& +\alpha_{g} \log \left(N_{\text {occ }}+1\right) \times N_{\text {septic pumps }} \\
& +\alpha_{g} \log \left(N_{o c c}+1\right) \times N_{\text {well pumps }} \\
& +\alpha_{10} \log \left(N_{\text {occ }}+1\right) \times N_{\text {dishwashers }} \times A l l o c_{\text {dishwashor }} \\
& +\alpha_{11} \log \left(N_{\text {occ }}+1\right) \times N_{\text {washerldyer }} \times A l l o c_{\text {washerldyer }} \\
& +\alpha_{12} \log \left(N_{\text {oco }}+1\right) \times N_{\text {water hoater }} \times A l l o c_{\text {water hoator }} \\
& +\alpha_{13} / s Z o n e 1 \times H a s A C \times C D D j N_{\text {days }} \\
& +\alpha_{14} H a s A C \times C D D \mid N_{\text {days }} \\
& +\alpha_{15} \text { HasElecOnly } \times I S M A P \times C \times U A \times\left(\frac{H D D}{N_{\text {days }}}\right) \\
& +\alpha_{16} \text { HasElec\&Wood } \times I S M A P \times C \times U A \times\left(\frac{H D D}{N_{\text {days }}}\right) \\
& +\alpha_{17} \text { HasEleckOther } \times \text { IsMAP } \times C \times U A \times\left(\frac{H D D}{N_{\text {days }}}\right) \\
& +\alpha_{18} \text { HasElecOnly } \times C \times U A \times\left(\frac{H D D}{N_{\text {days }}}\right) \\
& +\alpha_{19} \text { HasElec\&Wood } \times C \times U A \times\left(\frac{H D D}{N_{\text {days }}}\right) \\
& +\alpha_{20} \text { HasEleckOther } \times C \times U A \times\left(\frac{H D D}{N_{\text {days }}}\right) \\
& +\alpha_{21} \text { HasHPonly } \times I S M A P \times C \times U A \times\left(\frac{H D D}{N_{\text {days }}}\right) \\
& +\alpha_{22} H a s H P \& W o o d \times I s M A P \times C \times U A \times\left(\frac{H D D}{N_{\text {days }}}\right) \\
& +\alpha_{23} \text { HasHPonly } \times C \times U A \times\left(\frac{H D D}{N_{\text {days }}}\right) \\
& +\alpha_{24} \text { HasHP\&Wood } \times C \times U A \times\left(\frac{H D D}{N_{\text {days }}}\right) \\
& +\alpha_{25} / s \text { Vacant }
\end{aligned}
$$


TABLE 4.2. Definition of Terms in Equation (4.2)

\begin{tabular}{|c|c|}
\hline Term & Definition \\
\hline kWh & Total electricity use in the billing period \\
\hline Intercept & The regression intercept term \\
\hline$N_{\text {deyz }}$ & Number of days in the billing period \\
\hline $\log$ & The natural logarithm \\
\hline$N_{o c c}$ & The number of occupants in the home \\
\hline$N_{\text {sppliance }}$ & $\begin{array}{l}\text { The number of the indicated appliances in the home. For some appliances, this is } \\
\text { always either } 0 \text { or } 1 \text {. }\end{array}$ \\
\hline Alloc $_{\text {appliance }}$ & The monthly load allocation factor for the indicated appliance (see Lee et al. 1995) \\
\hline Incomelow & A dummy variable indicating household income is less than $\$ 25,000$ per year \\
\hline IncomeHigh & A dummy variable indicating household income is greater than $\$ 40,000$ per year \\
\hline IsOccDaytime & A dummy variable indicating the home is occupied during the day \\
\hline IsZone1 & A dummy variable indicating the home is sited in $\mathrm{CZ} 1$ \\
\hline HasAC & A dummy variable indicating the presence of an air conditioner \\
\hline HasElecOnly & $\begin{array}{l}\text { A dummy variable indicating the home has electric resistance heat with no backup } \\
\text { system }\end{array}$ \\
\hline HasElec\&Wood & $\begin{array}{l}\text { A dummy variable indicating the home has electric resistance heat with a wood- } \\
\text { burning backup system }\end{array}$ \\
\hline HasElec\&Other & $\begin{array}{l}\text { A dummy variable indicating the home has electric resistance heat with an } \\
\text { unspecified backup system }\end{array}$ \\
\hline HasHPonly & A dummy variable indicating the home has a heat pump with no backup system \\
\hline HasHP\&Wood & $\begin{array}{l}\text { A dummy variable indicating the home has a heat pump with a wood-burning } \\
\text { backup system }\end{array}$ \\
\hline CDD & Cooling-degree days for each month based on NOAA data \\
\hline HDD & Heating-degree days for each billing period, reference temperature $65^{\circ} \mathrm{F}$ \\
\hline UA & Building envelope load coefficient plus infiltration UA \\
\hline IsMAP & A dummy variable indicating a MAP home \\
\hline C & A constant to give the UA*HDD terms units of kWh/day \\
\hline IsVacant & A dummy variable indicating home was vacant during the specific billing period \\
\hline
\end{tabular}

\section{7}


TABLE 4.3. Estimated Coefficients in Equation (4.2)

\begin{tabular}{|c|c|c|c|c|c|}
\hline Coefficient & Value & t-statistic & Coefficient & Value & t-statistic \\
\hline Intercept & -2.15 & -1.76 & $a_{13}$ & 1.66 & 2.74 \\
\hline$a_{1}$ & -2.74 & -2.30 & $a_{14}$ & 1.34 & 3.47 \\
\hline$\dot{a}_{2}$ & 2.18 & 1.55 & $a_{15}$ & 0.104 & 4.31 \\
\hline$a_{3}$ & 5.01 & 4.36 & $a_{16}$ & 0.0405 & 0.79 \\
\hline$\alpha_{4}$ & 0.39 & 0.36 & $a_{17}$ & 0.322 & 5.24 \\
\hline$a_{5}$ & 2.84 & 2.69 & $a_{18}$ & 0.743 & 43.6 \\
\hline$a_{6}$ & 2.33 & 1.58 & $a_{19}$ & 0.418 & 15.0 \\
\hline$a_{7}$ & 2.20 & 2.54 & $\alpha_{20}$ & 0.291 & 6.82 \\
\hline$\alpha_{8}$ & 3.40 & 3.13 & $a_{21}$ & 0.187 & 4.06 \\
\hline$a_{9}$ & 1.98 & 2.41 & $a_{22}$ & 0.712 & 3.46 \\
\hline$a_{10}$ & 2.91 & 2.82 & $a_{23}$ & 0.583 & 20.0 \\
\hline$a_{11}$ & 0.056 & 0.05 & $a_{24}$ & 0.196 & 1.19 \\
\hline$a_{12}$ & 9.80 & 5.18 & $a_{25}$ & -14.1 & -9.48 \\
\hline $\begin{array}{l}\text { Note: The co } \\
\text { heating equip } \\
\text { standard t-sta }\end{array}$ & $\begin{array}{l}\text { ints imp } \\
\text { terms li } \\
\text { s. }\end{array}$ & $\begin{array}{l}\text { in this mo } \\
\text { he usual in }\end{array}$ & $\begin{array}{l}\text { y using engi } \\
\text { retation of sic }\end{array}$ & $\begin{array}{l}\text { ing inforn } \\
\text { ance bas }\end{array}$ & $\begin{array}{l}\text { ion in the } \\
\text { on the }\end{array}$ \\
\hline
\end{tabular}

To assess the performance of this model, we used it to estimate the energy consumption of homes as similar as possible to those in our baseline and MAP home samples. For most variables, we substituted the mean value for the region from our combined sample of homes. For heating systems, we used the mean proportion of each heating system by climate zone for the combined MAP and baseline home sample. Table 4.4 shows the long-term HDD and CDD values used in the analysis.

Table 4.5 compares the results from the model with the billing data for the MAP and baseline homes. Evaluating the fitted model with these assumptions resulted in the mean annual consumption values and differences between baseline and MAP home values ( $k W h$ ) shown in Table 4.5. 
TABLE 4.4. Weather Assumptions Used in Sample Home Estimates

\begin{tabular}{|c|c|c|c|c|}
\hline \multirow{2}{*}{\multicolumn{2}{|c|}{ Weather characteristic }} & \multicolumn{3}{|c|}{ Climate zone } \\
\hline & & 1 & 2 & 3 \\
\hline HDD & & 4834 & 6744 & 7689 \\
\hline CDD & & 22 & 179 & 74 \\
\hline (a) & \multicolumn{4}{|c|}{$\begin{array}{l}\text { CZs } 1,2 \text {, and } 3 \text { are represented by data from Seattle, Spokane, and Missoula, respectively. } \\
\text { We note that the HDD in Missoula are less than the threshold defined for CZ } 3 \text {. Nevertheless, } \\
\text { Missoula has been used routinely by the Northwest Power Planning Council to represent CZ } 3 \text {. } \\
\text { Cooling degree-days are calculated from National Oceanic and Atmospheric Administration } \\
\text { "normal" daily temperatures, i.e., long-term averages for each day of the year. These normals } \\
\text { comprise an unnatural "year" in that there are no extreme highs or lows. Thus, the degree- } \\
\text { days used for these regressions and for projecting savings differ substantially from those } \\
\text { calculated from data more representative of an actual year, such as Typical Meteorological } \\
\text { Year (TMY) data. }\end{array}$} \\
\hline
\end{tabular}

The comparisons revealed that 1) the model's consumption estimates were higher than the billing data values in all cases and 2) the amount that the consumption estimates from the model exceeded the billing data values was much larger for the baseline homes than for the MAP homes. One consequence of these results was that the differences between the baseline and MAP home consumption estimates from the model were consistently higher than the billing data differences.

We investigated these differences to determine what factors accounted for them. A major reason that the consumption estimated by the model exceeded the billing data values was that the weather during the billing period was about $10 \%$ warmer than the long-term average weather. Estimates from our model were all based on long-term weather data as they should be for program evaluation purposes.

A second reason that the model was likely to produce consumption estimates exceeding the billing data values was that we did not attempt to adjust our model estimates for the effect of occupants being gone during billing periods. Including the value of $a_{25}$ in Table 4.3 would reduce our consumption estimates a few hundred $k$ Wh per year. We did not attempt to include this effect, however, because we did not have adequate data to make an aggregate adjustment for it. 
TABLE 4.5. Comparison of Regression Model Estimates and Billing Data Without Adjustments, kWh/year

\begin{tabular}{|l|c|c|c|c|c|c||}
\hline \hline \multirow{2}{*}{ Climate Zone } & \multicolumn{2}{|c|}{ Baseline homes } & \multicolumn{2}{c|}{ MAP homes } & \multicolumn{2}{c||}{ Difference } \\
\cline { 2 - 7 } & $\begin{array}{c}\text { Billing } \\
\text { data }\end{array}$ & $\begin{array}{c}\text { Model } \\
\text { estimate }\end{array}$ & $\begin{array}{c}\text { Billing } \\
\text { data }\end{array}$ & $\begin{array}{c}\text { Model } \\
\text { estimate }\end{array}$ & $\begin{array}{c}\text { Billing } \\
\text { data }\end{array}$ & $\begin{array}{c}\text { Model } \\
\text { estimate }\end{array}$ \\
\hline \hline 1 & 16,800 & 18,540 & 14,500 & 15,600 & 2,300 & 2,930 \\
\hline 2 & 18,500 & 22,390 & 17,100 & 18,490 & 1,400 & 3,900 \\
\hline 3 & 19,300 & 23,770 & 19,100 & 20,270 & 200 & 3,490 \\
\hline Region & 17,600 & 20,380 & 15,800 & 17,040 & 1,800 & 3,340 \\
\hline \hline
\end{tabular}

The third, and main, reasion that the model produced relatively higher consumption estimates for baseline homes than MAP homes was that baseline homes were more likely to use non-electric backup heat. We used the mean proportion of heating system types to produce our model estimates for both baseline and MAP homes. For baseline homes, the proportion of homes with non-electric backup heat in the sample would be higher than the proportion we used in our model estimates. Consequently, the model's consumption estimates for baseline homes would be higher than the values from the billing data. Because the differences between the use of non-electric heat in MAP and baseline homes observed in our sample appeared to be artifacts of the sample, we used the average proportions for the combined sample to estimate electricity consumption.

The available data did not permit us to adjust our model estimates consistently for these three factors. We were able, however, to make some partial adjustments to estimate the effects. These tests showed that with these three adjustments the model would produce consumption estimates within about $3 \%$ of the billing data values. This demonstrated that the model replicated the measured consumption values very closely. It also showed the significance of non-electric heat and weather characteristics in efforts to estimate electricity consumption. 


\subsection{DISCUSSION OF REGRESSION COEFFICIENTS}

In this section, we discuss the individual regression coefficients and how they compare with our expectations. Most of the coefficients in the model are consistent with expectations in terms of sign, although not necessarily in terms of magnitude. Except for the UA*HDD terms, which are the primary coefficients of interest, our concern for the coefficients is that they appropriately normalize between the two samples for consumption determinants not explicitly associated with the MAP program. We kept any term in the regression for which the estimated coefficient had the expected sign, without regard to its magnitude.

Income. The coefficient for low-income households $\left(\alpha_{1}\right)$ shows a reduction in annual electricity consumption of about $1,000 \mathrm{kWh}$ relative to a middle-income household. A high income $\left(a_{2}\right)$ is associated with an increase of about $800 \mathrm{kWh} / \mathrm{yr}$.

Daytime occupancy. Homes that are occupied during the day $\left(a_{3}\right)$ show annual consumption about $1,800 \mathrm{kWh}$ higher than homes in which all occupants are gone during the day. The direction of this effect is as expected, but the reasonableness of the estimated magnitude is difficult to judge. Homes occupied during the day are expected to consume more energy for lighting, cooking, water heating, and other miscellaneous uses, but they are also expected to have a lower incidence of daytime thermostat setback. This latter effect is not best modeled by a simple indicator variable; however, nesting the HDD slope terms within the daytime occupancy variable would considerably complicate the already-nested model and the interpretation of its coefficients. The fraction of homes occupied during the day is approximately equal in the two samples.

Appliance Inventories. All appliance count coefficients have the expected positive sign indicating additional consumption. Two of the coefficients--waterbed heaters and clothes washers/dryers ( $\alpha_{4}$ and $\alpha_{11}$ )--have very large standard errors, but were retained in the model because of a strong expectation of a non-trivial impact on consumption. The remaining appliance coefficients are at least moderately significant and are discussed below.

- Computers $\left(\alpha_{5}\right)$ - Presence of a computer in the home increases annual consumption by about $1,000 \mathrm{kWh}$. This is roughly equivalent to a 115-Watt device running 8760 hours per year. Because this value is larger than the computer alone is likely to consume, this term may be acting as a proxy for other end uses.

- Refrigerators and Freezers $\left(a_{8}\right.$ and $\left.a_{7}\right)$ - The refrigerator coefficient implies an annual consumption of about $850 \mathrm{kWh}$. This estimate is relatively close to the 
average for new refrigerators sold in 1992, lying between the sales-weighted national average consumption for the two most common refrigerator types sold, top-mount freezer and side-by-side refrigerators. ${ }^{\left({ }^{(a)}\right.}$ Because over $90 \%$ of new manufactured homes in the Pacific Northwest come equipped with refrigerators and they are likely to be smaller than those in site-built homes, this estimate appears to be reasonable. However, it is likely that the virtual lack of variation. in this variable (nearly all homes have exactly one refrigerator) results in a distorted coefficient in this relatively small sample. The freezer coefficient indicates that each freezer increases annual consumption by about $800 \mathrm{kWh}$. This is slightly more than half the estimates from Bonneville's Regional End Use Metering Program, REMP (Cahill, Ritland, and Lin-Kelly, 1992), but the higher efficiency levels of newer freezers and smaller sizes might explain the smaller consumption estimates from our analysis.

- $\quad$ Septic and Well Pumps ( $\alpha_{8}$ and $a_{9}$ ) - Assuming 2.5 occupants, these coefficients imply annual consumption of about $1,500 \mathrm{kWh}$ for septic pumps and $900 \mathrm{kWh}$ for well pumps.

- Dishwashers $\left(a_{10}\right)$ - Presence of a dishwasher implies an additional annual consumption of about $1,300 \mathrm{kWh}$, assuming 2.5 occupants. The vast majority of this is expected to be differential hot water consumption. Average measured consumption of the dishwasher itself under REMP was only about $120 \mathrm{kWh} / \mathrm{yr}$.

- Water heaters $\left(a_{12}\right)$ - Although we expect hot water consumption to be a stronger function of number and type of occupants than number of water heaters, we find a significant coefficient indicating about $4,400 \mathrm{kWh} / \mathrm{yr}$ per water heater. This value is extremely close to the average household electricity consumption by water heaters of $4,700 \mathrm{kWh} / \mathrm{yr}$ measured in REMP. However, because very few homes in our sample have more than one water heater, this correspondence is likely fortuitous.

Cooling Degree-Days. The coefficient on cooling degree-days $\left(a_{14}\right)$ of 1.34 implies that cooling is responsible for a very small fraction of weather-related electricity consumption. The average number of annual cooling degree-days experienced by the homes in our sample is only 141, implying an annual cooling energy consumption of less than 200 $\mathrm{kWh}$. It is interesting that the marginal effect on the cooling slope coefficient of a homes being located in $C Z 1\left(a_{13}\right)$ is 1.66 , which more than doubles the effective cooling slope

(a) Personal communication, July 8, 1995, Association of Home Appliance Manufacturers (AHAM), Chicago, Illinois. 
in that region. This is not unexpected considering that outdoor temperature effects are a relatively small determinant of cooling needs compared with solar and internal heat gains. Because $\mathrm{CZ} 1$ has extremely small values of annual cooling degree-days, the amount of cooling per degree-day is higher in that region.

Heating Degree-Days. As expected, the coefficients for the terms that incorporate UA and HDD are between zero and one, and they vary as a function of the type(s) of heating system present in the home. Electric resistance-only homes have a coefficient $\left(a_{18}\right)$ of 0.743 ; homes with electric resistance plus wood as a backup system have a coefficient $\left(a_{19}\right)$ of 0.418 ; and homes with electric resistance plus some other type of backup system have a coefficient $\left(a_{20}\right)$ of 0.291 . As expected, coefficients for heat pump homes are lower, indicating the higher efficiency of operation. Heat pump-only homes have a coefficient $\left(\alpha_{23}\right)$ of 0.583 , while homes with a heat pump and wood back-up heat have a coefficient $\left(a_{24}\right)$ of 0.196 .

Somewhat contrary to expectations, MAP homes have a consistently positive and statistically significant incremental slope value. To facilitate viewing this, Table 4.6 shows the baseline UA*HDD coefficients and the MAP coefficients (obtained by adding the baseline coefficients and the MAP coefficients).

The clear effect of MAP is to increase heating energy consumption relative to what would be expected from a simple UA*HDD calculation for a baseline home with a similar UA. Another way of stating this is that the effective UA of a MAP home tends to be higher than engineering calculations would suggest, or the effective UA of a baseline home tends to be lower than calculations would suggest. There are several possible explanations for this.

First, the model uses the assumption that the response to HDD is linear and proportional to UA. This is not necessarily correct over the entire HDD range, however, because the balance temperatures of many of these homes are likely to be less than $65^{\circ} \mathrm{F}$, the reference temperature used here to calculate HDD. There are conditions for which monthly HDD (base $65^{\circ} \mathrm{F}$ ) exceeds zero, yet no heating occurs. Our model fits a slope to all these observations. It is likely that the fitted slope is estimated to be higher for MAP homes because the effect of these non-heating conditions is more pronounced. 
TABLE 4.6. Baseline and MAP Home Heating Coefficients by System Type

\begin{tabular}{||c||c|c|}
\hline \multirow{2}{*}{ Heating System Type } & \multicolumn{2}{|c|}{ UA*HDD Adjustment } \\
\cline { 2 - 3 } & Baseline & MAP \\
\hline \hline Electric Resistance & 0.743 & 0.847 \\
\hline only & 0.418 & 0.459 \\
\hline w/ wood backup & 0.291 & 0.613 \\
\hline w/ other backup & & \\
\hline Heat Pump & 0.583 & 0.770 \\
\hline only & 0.196 & 0.908 \\
\hline w/ wood backup & & \\
\hline
\end{tabular}

Second, MAP homes may be influenced more than other homes by the effect of ventilation on heating energy consumption. The MAP specifications require installation of a whole-house ventilation system capable of delivering from 45 cubic feet per minute (CFM) (1-bedroom) to 90 CFM (4-bedroom) of exhaust air controlled by a 24-hour timer. Baseline homes have no similar ventilation requirement. However, because we have no information regarding the actual use of such ventilation systems, the UAs included in the regression equation do not differentiate infiltration between MAP and baseline homes. To the extent that MAP homes have higher air exchange rates due to mechanical ventilation than baseline homes, we would expect the UA*HDD regression coefficients for MAP homes to be higher.

Although the average magnitude of this effect is not known, the energy-use effect of mechanical ventilation can be significant. A 90-CFM fan, for example, could increase the effective UA of a MAP home by about $50 \%$ when it operates. A crude estimate of the annual heating effect (in $\mathrm{kWh}$ ) can be obtained by multiplying the additional UA by the heating degree-days for a location. For example, a 90-CFM fan would increase the home's UA by almost $100 \mathrm{Btu} / \mathrm{hr}-{ }^{\circ} \mathrm{F}$. If the fan runs 8 hours every day in Spokane, one might expect the additional annual heating load $(\mathrm{kWh})$ to be as much as

Third, many home owners practice a form of zoning by shutting off certain rooms-usually unused bedrooms--during part of the day or even all year. The effect of this behavior is to lower the effective UA of the home as seen by the thermostat. The heat- 


$$
k W h_{\text {ventlation }}=\left(100 \frac{B t u}{h r \times F} \times 6744 H D D\right) \times \frac{8 \frac{h r}{d a y}}{3413 \frac{B t u}{k W h}}=1581
$$

flow resistance from the thermostat to the outdoor air includes the doors and partition walls of the closed-off rooms. The prevalence of this practice in the MAP and baseline homes is not known. However, it can be shown that this zoning effect is present to some degree even in homes where it is not actively practiced. Whenever the HVAC system fan is not running, there is an additional resistance to heat flow between the -thermostat and the outdoor air because of the distance to the ends of the home. The calculated UA of the envelope is biased upward because it does not account for this added thermal resistance.

This implicit zoning effect is present to some degree in all homes, but it can be readily shown that the fractional reduction in UA is considerably smaller in a better-insulated (e.g., MAP) home than in a less-insulated (e.g., baseline) home. This effect is similar to the well-known diminishing-returns effect of an increment of insulation having less value when added to an already well-insulated structure than when added to a poorly-insulated structure. The reduced effectiveness of this implicit zoning in a MAP home would manifest itself to the occupants as a more uniform temperature throughout the home. This added amenity is often mistakenly attributed to occupant take-back effects, but it is purely a consequence of thermal physics, not any change in occupant behavior.

The magnitude of the effect is difficult to estimate, given the large variations and uncertainties in home layouts and occupant behavior. Miller and Pratt (1990) have shown that the effect of active zoning can be significant, reducing the benefits expected from a conductive UA change by anywhere from $15 \%$ to over $50 \%$, depending on the number of rooms closed off by the occupants.

\subsection{DISCUSSION OF MODELING ISSUES}

The cross-sectional observations underlying our estimation of the model parameters can give rise to heteroskedastic--or non-constant variance--error terms across units. While OLS estimators of the slope coefficients are unbiased in this situation, the estimates of the standard errors are not. Weighted least squares methods can be used to transform the model so that the classical least squares properties result and the least squares estimator is minimum-variance, as well as unbiased. 
By conventional tests, ${ }^{(a)}$ evidence of non-constant variance in our analysis was inconclusive. We examined two generally recognized techniques for this diagnostic. First, weighted least squares regressions of the basic model represented in Equation (4.2) were examined with income levels and occupancy level as weighting variables; these are customary factors that can account for a non-constant variance in dependent variables such as usage. We found only very slight differences in the resulting slope coefficients for all variables. Second, we used a straight-forward "robust" least squares procedure. This estimator attempts to correct for non-constant variance without a weighting variable by using normalized residuals to produce a consistent estimate of the model variance. This procedure also produced only a small reduction in the estimated model variance and estimated standard errors on the coefficients, in particular for the space heat related variables. Without more refined analysis of this issue, it appears that while heteroskedasticity may be present, it is not a significant concern in this model.

In the course of the initial least squares estimation runs of the model in Equation (4.2), serial correlation in the model's disturbance terms was a persistent outcome. Although least squares regression in this instance still possesses the desirable property of unbiased estimated coefficients, the estimator of the variance of the coefficient estimate is biased downward. The most suitable estimation procedures to address this problem, such as maximum likelihood estimations, were difficult to implement in our sample of time series observations of panel data with an unbalanced number of observations. We employed the more direct, classical Cochrane-Orcutt procedure instead. The resulting estimated serial correlation parameter was similar in magnitude to that obtained in the analysis by Regional Economic Research discussed in Chapter 6. ${ }^{(b)}$

Frequently, panel data formulated from consumer surveys can be subject to considerable response error. The soúrces of incorrect answers or response error can be numerous, and it is customary to pre-test the survey instrument prior to implementing it on the targeted sample. This was done in our study (see Sandahl, Lee, and Chin [1995]). Nevertheless, it is possible that significant response error might remain, leading to the presence of outliers. The presence of such outliers on least squares estimates could have significant effects, especially on the space heating estimates, as well as the overall quality of the estimated results.

To address such problems, we used a procedure called "studentized-t residuals" (Belsley, Kuh, and Welsch [1980]) rather than a simple screening of the residuals. The technique normalizes the residuals to develop a scaling factor or cut-off level. This

(a) Such as the tests due to Gleser (Gujarati [1988]).

(b) Personal communiçation with RER staff, July 1995. 
information helps identify overly influential observations (highly "leveraged"), independent of the residual itself. Generally, the tradeoff is in terms of increased sample precision for the point estimates in exchange for lost degrees of freedom. There is the added limitation that the estimated standard errors are no longer of the minimum variance type, conventionally associated with the least squares estimator. Nevertheless, we implemented the procedure as a diagnostic tool to analyze whether there was a perceptible effect on the estimated slope coefficients. In all instances, the standard error of the regression declined as expected, but this estimator changed the coefficient values negligibly from the unfiltered sample values.

\subsection{CONFIDENCE INTERVALS}

The estimates of energy savings attributable to MAP presented in this report and elsewhere typically have been point estimates. Such apparent "precision" belies the effects of random error that are inevitably present in impact evaluations using either engineering or conditional demand analyses, or other methods. Such error can originate in sampling error, measurement error, and error in the structural model. This section discusses the development of statistical confidence intervals that give some indication of how probable it is that energy savings estimates for the population fall within a range of the point estimates. This method could be applied to the estimates in Table 4.5 and was extended to the estimates of program savings presented in Lee et al. (1995).

Our simplified method for developing confidence intervals rests on the error variance of the regression model. They reflect how precise our estimated heating slope coefficients are, given all else held constant in the usage demand equation. Using standard statistical procedures, the conventional 1.96 standard deviations from the mean are used to establish the range within which there is a $95 \%$ probability that the true value lies. Algebraically, the confidence intervals are defined as

$$
\left[B^{\prime(B)} \pm 1.96 \times S^{\prime}\left(B^{(B)}\right)\right] \times U A \times H D D
$$

and

$$
\left[B^{\prime(M)} \pm 1.96 \times S^{\prime}\left(B^{(M)}\right)\right] \times U A \times H D D
$$

where the prime denotes the coefficient estimate and the $(B)$ and $(M)$ superscripts denote baseline and MAP units, respectively. $S^{\prime}(B)$ represents the estimated standard errors of the coefficients, $B$, associated with each heating type in the regression model. 
The next step is to derive the variance for the difference between two, independent random variates (one for baseline and one for MAP homes). Since each is assumed to be a random variable from a univariate probability distribution, they are independent and their covariance is identically equal to zero. ${ }^{(a)}$ In this case, the variance of a random variable that is the result of taking the difference is equal to the sum of the variances of the variables, and the expression for the $95 \%$ confidence interval for the estimated savings is.

$$
D_{i j} \pm 1.96 \times\left[S^{2}\left(b_{i j}\right)+S^{2}\left(m_{i j}\right)\right]^{1 / 2}
$$

$D_{i j}$ represents the difference in consumption due to MAP for heat type in $C Z j$, and $S^{2}\left(b_{i j}\right)$ and $S^{2}\left(m_{i j}\right)$ are the variance estimates of the terms related to space heat for baseline and MAP homes.

The estimated confidence intervals for estimated savings are reported in Table 4.1 of Lee et al. (1995). The implied coefficient of variation (the ratio of the standard error of the savings estimate to its mean) is about 0.18 for homes heated with electric furnaces. For homes with heat pumps the ratio is 0.56 , reflecting the larger variance in the considerably smaller sample of homes with heat pumps.

We note that the results in Lee et al. (1995) represent model predictions at values different than the means of the data contained in the estimating sample. This creates no major difficulties, except that the theory of prediction using regression methods indicates that the error variance must be augmented with information that reflects this deviation from sample means. ${ }^{(b)}$ Several random checks of this possibility and its impact revealed, however, only extremely small influences on the width of the confidence bands. for the values evaluated. This result is the outcome of the large number of observations used in the regression itself and the fact that the assumptions underlying the estimates presented in Lee et al. (1995) fall well within the range of sample values.

(a) If they are from a joint, bivariate distribution, they are either a baseline home or not, so the covariance would be zero.

(b) This is the source of the widening or "flared", predicted confidence bands as extreme values in the set of predictors or explanatory variables are evaluated. 


\subsection{REVIEW OF PRE-PROGRAM ANALYSIS}

In this chapter, we put forth several factors that could contribute to differences between pre-program engineering consumption and savings estimates and the estimates from our MAP evaluation. This information may be relevant to analyses of other programs as well.

\subsection{INTRODUCTION}

The primary purpose of this evaluation was to assess the performance of homes built to the MAP specifications relative to the performance of similar non-MAP homes. Although not a major objective of this study, it was informative to compare the evaluation results with the pre-program engineering estimates.

The purpose of this exercise was twofold: to help explain differences between preprogram expectations and observed results, and to inform the analysis process so that predictions of future program energy savings might be improved.

Predicting the performance of un-built homes is generally done with thermal energy simulation software. Such software requires the selection and input of the key thermal characteristics of the homes in question as well as numerous assumptions regarding occupant behavior and environmental influences. The pre-program estimates of MAP savings were based on analyses using the SUNDAY computer program (see Baylon et al. [1991] and Baylon and Davis [1993]).

Selection of appropriate input assumptions to analyze un-built homes is a difficult task at best. It is unreasonable to expect that analysts would be able to model accurately all important influences on building energy consumption. When data are available, they are typically used to establish input assumptions for the most important variables. Otherwise, judgment is used to identify reasonable assumptions.

In assessing the performance of homes actually constructed and occupied, it is impossible to measure the energy savings from a program such as MAP. Although we can measure the actual energy consumption of a home built to the MAP specifications, it is impossible to know how thermally efficient it would have been without the MAP influence or, even if that were known, to know how the home would have actually performed. Thus, evaluation of program effects involves much the same process of establishing assumptions as the pre-program modelling. 
Establishing the appropriate baseline for comparison is a key source of uncertainty in evaluating program savings. In this evaluation, we used a random sample of homes built immediately prior to implementation of MAP to represent the baseline for initial analysis purposes. There is no guarantee that these homes are at the efficiency level they would have been had MAP or the Super Good Cents Program never been implemented. Indeed, there is reason to believe that MAP and its predecessors did influence the design of these homes. Judgment is required to account for these effects in a reasonable manner.

Once a baseline is established, its energy performance must be modelled somehow. However, when actual energy consumption data are available, assumptions need not be made for all the variables required in the pre-program modelling. The influences of occupant behavior, for example, are usually implicit in the models used to analyze actual energy consumption data.

\subsection{DIFFERENCES BETWEEN PRE-PROGRAM AND PNL ANALYSES}

This section hypothesizes some potential reasons why the MAP energy savings that we estimated might differ from the pre-program estimates. The two studies identified earlier provided information about the pre-program estimates.

- House size and component characteristics. Pre-program savings estimates relied heavily on assumptions about house size, house component (ceiling, wall, etc.) sizes, and insulation levels. Baylon and Davis (1993) assumed that the average house had $1,568 \mathrm{ft}^{2}$ of conditioned floor area, which exceeded the average we found from our survey by $6.7 \%$. Under the simplistic assumption that heating energy use is proportional to shell area, we would expect pre-program savings estimates to exceed our findings by over $5 \%$.

- Infiltration and ventilation rates. The pre-program modelling analysis assumed infiltration and ventilation rates were identical for MAP and baseline homes. Air exchange rate measurements were not available for our evaluation, so there was no way to either verify the pre-program assumption or quantify any suspected differences. However, we do know that all MAP homes are required to have mechanical ventilating capabilities not typically installed in non-MAP homes. As discussed in Section 4.4, the effect of the ventilating equipment on heating load can be quite large. Although there is anecdotal evidence that many occupants reduce the ventilating hours or disable the ventilation altogether, we expect the overall observed savings to be smaller than estimated by a simulation that assumed no difference at all between the two samples. 
- Internal and solar gains. The energy required to maintain a home at a specified indoor temperature is the fundamental quantity computed by energy simulation models. That energy requirement (the "load") can be met in a number of ways-heat introduced by the furnace, heat generated from lights, appliances, and other equipment in the home, and solar gains through glazing. The heat introduced by the furnace is the quantity of interest. Unfortunately, in the pre-program modelling, converting from the calculated load to the heating energy consumption requires assuming a level of internal gains--the average Watts of heat generated by lights and appliances. Although that estimate can be based on data from prior submetering studies, considerable judgment is required to establish it. Indeed, it is often the internal gains assumption that is the primary parameter varied in an attempt to match modelled results to metered results.

The analysis of billing data does not directly indicate how much electricity is consumed for heating versus other internal equipment (or outside equipment). Our regression analysis attempts to control for non-heating electricity uses, but there is no guarantee that the fraction of a home's heating load met by internal gains is the same in the MAP and baseline samples. It is difficult to know whether the pre-program assumptions tend to bias the estimates relative to actual home usage.

Solar gains are typically modelled based on the assumption that glazing is equally distributed among the four cardinal orientations, an attempt to account for the diversity of true home orientations. We have no information on home orientation, so cannot hypothesize regarding expected orientation biases. The differences that we observed in typical window areas for the MAP and baseline homes would probably result in our analysis overestimating MAP heating savings by a small amount.

Random vacancies. This is perhaps the most important variable that is not easily and accurately incorporated into the pre-program modelling. Most simulation software, including SUNDAY, assumes that occupant behavior is regular-scheduled consistently from day to day, month to month. The pre-program MAP estimates are based on an assumption consistent with a house that is conditioned year-round, albeit with a night thermostat setback. In reality, some occupants do not set back their thermostat, while others set it back at night and during the day when unoccupied. People take vacations, during which they usually turn back the thermostat and may even turn off the water heater.

Our understanding of the semi-random nature of occupancy (daytime vacancies, vacations, etc.) is insufficient to allow quantification of its effect. However, because the pre-program modelling assumptions did not account for any extended vacancy periods, we expected that the effect of random vacancies would be to lower heating energy consumption relative to the engineering 
estimates. Our evaluation methodology attempts to control for such vacancies in a simplified way, but the diversity of such behavior is not easily treated in a simple regression analysis. There is undoubtedly some influence of random vacancies implicit in the heating coefficients of our regression.

- Zoning. As with random vacancies, we have no data quantifying the extent of zoning practices in the homes under study. But many residents do close off some rooms or otherwise arrange to heat only portions of the home at any one time. Additionally, as discussed in Section 4.4 , there is an implicit zoning effect resulting from the distance from a homes thermostat to the outer walls. While we cannot quantify this effect, neglecting it in the pre-program simulations very clearly results in an overestimation of MAP heating savings.

- Thermostat settings. It has often been postulated that owners of higherefficiency homes will "take back" some of the potential energy savings by raising thermostat settings in response to a perception of less cost impact. Whether this happens in MAP homes is unknown. ${ }^{(a)}$ But if present, the practice clearly would reduce program savings relative to engineering estimates because the preprogram simulations assumed the same thermostat setpoint for both MAP and non-MAP homes.

A second, and probably more significant, issue is that the pre-program simulations assumed a constant thermostat setpoint instead of separate settings for daytime and nighttime. The constant setpoint chosen was a weighted value intended to represent the average daily setpoint behavior of large numbers of . homes, some of which practice night setbacks and some of which dont. The same average setpoint was assumed for both MAP and non-MAP homes.

Assuming the same constant setpoint for both samples introduces a bias into the pre-program estimates of energy savings. A constant setpoint causes SUNDAY to assume that the home is held at that temperature at all times during the heating season. However, if two homes, one heavily insulated and the other not, practice exactly the same thermostat schedule that includes a night setback, the heavily insulated home will maintain a higher average temperature than will the other home. When the thermostat setting is lowered at night, the temperature in the well-insulated home will decay more slowly than in the other home. So it is an error to simulate with a single constant (average) temperature as a proxy for a more complex thermostat strategy when homes of differing thermal conductance are involved.

(a) Thermostat setpoint and setback survey data suggested that occupants of MAP and baseline homes behaved almost exactly the same. 
To attempt to quantify the potential magnitude of this bias, we conducted a simple test using the SUNDAY software. Two prototype homes were designed to approximately represent non-MAP (UA $\left.=404 \mathrm{Btu} / \mathrm{hr}-{ }^{\circ} \mathrm{F}\right)$ and MAP $(\mathrm{UA}=235$ $\mathrm{Btu} / \mathrm{hr}{ }^{\circ} \mathrm{F}$ ) homes. Each was simulated with the same night setback thermostat strategy $\left(68^{\circ} \mathrm{F}\right.$ with 8-hour night setback to $\left.60^{\circ} \mathrm{F}\right)$ to compute annual heating consumption. We then identified (iteratively) the constant thermostat setpoint for each home that would result in the same annual heating consumption. The results are shown in Table 5.1. Depending on the climate, the "MAP" home's average temperature (equivalent constant setpoint) is between a half degree and one degree higher than that of the "baseline" home. If this is not accounted for in a constant-setpoint simulation, the effect is always to overestimate the heating savings of the MAP home. The savings error ranges from $3.1 \%$ in Spokane, to over $10 \%$ in Seattle when the setpoint appropriate for a MAP home is used in simulating both homes.

TABLE 5.1. Setback Effects

\begin{tabular}{|c|c|c|c|}
\hline Variable & City & $\begin{array}{c}\text { Baseline } \\
\text { home } \\
(\cup A=404)\end{array}$ & $\begin{array}{c}\text { MAP. } \\
\text { homes } \\
(\mathrm{UA}=235)\end{array}$ \\
\hline \multirow{2}{*}{$\begin{array}{l}\text { Heating load with setback strategy } \\
\text { (kWh) }\end{array}$} & Seattle & 8,699 & 3,277 \\
\hline & Spokane & 12,071 & 5,057 \\
\hline \multirow{2}{*}{$\begin{array}{l}\text { Constant setpoint that results in the } \\
\text { same heating load as the setback } \\
\text { strategy }\left({ }^{\circ} \mathrm{F}\right)\end{array}$} & Seattle & 65.78 & 66.56 \\
\hline & Spokane & 65.48 & 66.11 \\
\hline \multirow{2}{*}{$\begin{array}{l}\text { Heating load error when simulated } \\
\text { at the other home's equivalent } \\
\text { setpoint (kWh) }\end{array}$} & Seattle & 565 & -253 \\
\hline & Spokane & 421 & -218 \\
\hline \multirow{2}{*}{$\begin{array}{l}\text { Heating load error at other setpoint } \\
\text { (\%) }\end{array}$} & Seattle & 6.5 & -7.7 \\
\hline & Spokane & 3.5 & -4.3 \\
\hline \multirow{2}{*}{$\begin{array}{l}\text { Error in calculated heating savings } \\
\text { (\%) }\end{array}$} & Seattle & 10.4 & 4.7 \\
\hline & Spokane & 6.0 & 3.1 \\
\hline
\end{tabular}




\subsection{CONCLUSIONS}

We have discussed a number of modelling and evaluation factors and assumptions that could cause discrepancies between the pre-program savings estimates and our billingdata based estimates. Most bias the initial savings estimates upward, which is consistent with our findings. Because most of the specific effects are difficult to quantify, however, the overall anticipated bias cannot be calculated. Several of the effects could have a potential impact on savings in the $5 \%$ to $10 \%$ range. If these effects were compounded, they might explain much of the apparent discrepancy between our findings and the initial pre-program estimates. 


\subsection{REVIEW OF UTILITY EVALUATION ANALYSIS}

Regional Economic Research (RER) conducted an evaluation of MAP (the "IOU study") covering a time period similar to the period that we studied (RER 1994). It analyzed electricity usage in both MAP and control homes within the service territories of three of the region's investor-owned utilities (IOUs)--Portland General Electric, PacifiCorp, and Idaho Power Company--that participated in MAP. The study employed both engineering estimation and econometric estimation using a conditional demand model.

This chapter serves to put both the IOU study and PNL analysis in a common context, given their obvious analytical and sample similarities. The primary intent of doing so is to see if additional insights and lessons can be learned for understanding household electricity consumption, in general, and conservation program impacts, in particular. This discussion is not intended to deem the superiority of one study over the other, inasmuch as a more thorough assessment of the studies would be required and limitations on project resources, work scope, and data served to constrain both research strategies.

\subsection{OVERVIEW}

This review of the IOU study addresses three general areas. First, it discusses the IOU study and the PNL analysis (as developed in detail in Chapter 4) within the broad taxonomy of models used to explain household electricity demand and to assess the impacts of programs such as MAP. Second, it examines the mechanics of the particular model formulated in the IOU study. This serves to highlight some of the features that distinguish the IOU and PNL studies and helps explain the differences in the results produced by the studies. Third, this review compares and contrasts the models in terms of their implications for non-space conditioning end-uses. These comparisons can provide additional insight into the extent to which the reliance on billing data (which aggregates across all end-use demands) can blur end-use differences, even though space heating and other end-uses can be treated independently. ${ }^{(a)}$ This review chapter also serves to alert the reader to the fact that misspecifications and omitted effects in either study, across the range of end-uses, could be the source of bias in the resulting program savings estimates, or at least account in part for differences in the estimates.

(a) Significant exceptions to this independence exist. For instance, internal heat gains from appliances could lower space heat energy consumption slightly, but nevertheless systematically, over the seasons.

\section{1}


All residential energy demand econometric models rest on the distinction that energy use is a derived demand: units of electricity do not yield utility to the household directly. Instead, electricity is demanded as an input into household activities that provide direct benefits. For example, the entertainment provided by a TV is demanded directly, but the demand for electricity to power it is a derived demand.

Conditional demand analysis (CDA) pursues this logical structure by explicitly identifying all energy using appliances and equipment in a dwelling to account for total energy usage. Early CDAs, constrained primarily because of limited survey information on household characteristics, were simply analysis of covariance models (for example, Parti and Parti [1980]). With more robust sample information on appliance stocks and household demographics, recent approaches more fully represent the derived demand and the factors that affect it. Recent studies permit analyzing the utilization rate of an appliance, and the energy it consumes, taking into account the effect of prices, income, household demographics, the structure's physical configuration, and climate factors. Both the "thermal-behavior integrated" and "statistically adjusted engineering" (SAE) models specified in the IOU study are of this variety, as is PNL's model. ${ }^{(a)}$

Adopting the notation employed in the IOU study for discussion purposes, we let the following represent the essential elements of the ith household's electricity usage in period $t$ (with an underscored variable indicating a vector or array of elements):

$$
\begin{aligned}
& \mathrm{KWh}_{\mathrm{i}, \mathrm{t}}=\text { electricity use in ith unit in period } \mathrm{t} \\
& \mathrm{AF}_{\mathrm{i}} \quad=\text { appliance types, differentiated by features, in household } \mathrm{i} \\
& \mathrm{EDC}_{\mathrm{i}}=\text { economic and demographic characteristics of the ith unit } \\
& \mathrm{WC}_{\mathrm{i}, \mathrm{t}}=\text { weather influences at the ith site in period } \mathrm{t} \\
& \mathrm{S}_{\mathrm{i}, \mathrm{k}} \quad=\text { the presence of the } k \text { th appliance type in the } i \text { th unit } \\
& \mu_{\mathrm{i}, \mathrm{t}} \quad=\text { a randomly distributed disturbance term for the ith unit at t. }
\end{aligned}
$$

The traditional CDA model is then șummarized as

(a) While the IOU study specified and estimated two CDA models, the SAE model is used as the preferred model for evaluating program impacts. For this. reason, we do not discuss the thermal-behavior integrated model further. 


$$
k W h_{i, t}=a_{0, i}+\Sigma_{k=1, \mathrm{i}} f^{(k)}\left(\underline{A F_{i}}, \underline{E D C}, W C_{i}\right) \times S_{i, k}+\mu_{i, t}
$$

Since the usage from a given appliance or end-use is the result of the utilization rate for the item, the functions $f^{\text {tw }}$ have essentially a UEC (unit energy consumption) interpretation. Simplified CDA specifications designate the $U_{E C}$ as a fixed parameter or constant. The $f^{(\mathbf{k})}$ in Equation (6.1) generalizes the UECs to be functions of a broad range of factors.

SAE versions augment this CDA with extraneous information developed from engineering studies. Using the notation of the traditional CDA model from above, the SAE model can be written generically as

$$
k W h_{i, t}=a_{0, i}+B_{1} \times E s t_{i, t} \times S_{i, 1}+\sum_{k=2, n} f^{(k)} \times S_{i, k}+\mu_{i, t}
$$

where $\mathrm{Est}_{\mathrm{i}, \mathrm{t}}$ is the extraneous information in the form of an engineering analysis estimate of space heat energy consumption for the heating type $(k=1)$. The estimated $B_{1}$ coefficient "adjusts" the heating load based on the actual total load of the household, including both space conditioning and non-space conditioning uses. A value of $\beta_{1}$ equal to unity indicates no adjustment to the engineering estimate, while an estimate of $B_{1}$ less than unity indicates that the engineering estimate overstates actual space heat usage. A value greater than unity suggests that the engineering estimate underestimates the space heat use embedded in the actual billed usage and, therefore, the engineering estimate would have to be adjusted upward to be consistent with observed behavior.

Typically, engineering estimates tend to overstate space heating usage in houses because behavioral elements that partly determine actual usage are absent in the strict engineering simulations. Physical phenomena not adequately modeled in most simulations also can contribute to overstated space heat usage. As a result, one would normally expect to encounter a $\beta_{1}$-estimate that is less than unity. ${ }^{(a)}$

An SAE formulation strives to combine the best of both the engineering and the more behaviorally oriented CDA approaches. The strength of the pure engineering models lies in the rigorous representation of the thermal physics of the building. CDA models permit the explicit incorporation of behavioral responses to a wide range of economic and demographic factors, something that the engineering formulations are not intended to do. However, special care and assumptions are required for this integration of the two to produce reliable program evaluation results.

(a) Chapter 5 discusses some of the mechanisms that tend to bias engineering model estimates of space heat loads upward. 


\subsection{IMPLICATIONS OF THE UTILITY STUDY APPROACH}

The IOU study departs some from this general SAE framework. Adopting again some of the study's notation for purposes of convenience, the formulation starts out as

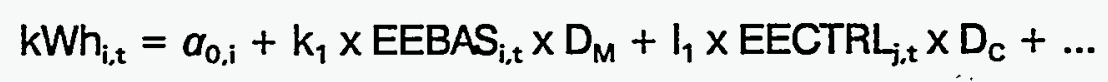

where

$$
\begin{aligned}
& \text { EEBAS }_{i, t}=\begin{array}{l}
\text { the engineering simulation predicted usage for the ith MAP unit at } \\
\text { time } t
\end{array} \\
& \text { EECTRL } L_{j, t}=\text { the engineering simulation predicted usage for the } j \text { th control house } \\
& D_{M} \text { and } D_{c}=\quad \begin{array}{l}
\text { dummy variables denoting the house type, MAP or control, } \\
\text { respectively. }
\end{array}
\end{aligned}
$$

The two coefficients, $k_{1}$ and $l_{1}$, are the estimated adjustment coefficients that scale the engineering predictions for both housing types to actual billing usage in the SAE models framework. As discussed above, $k_{1}$ and $l_{i}$. would be expected to be less than unity in practice and very possibly different from one another. For a number of reasons relating to both behavioral factors and physical ones, $k_{1}$ is likely to be greater than $l_{1}$; that is, the engineering spaçe heat estimates for a control home are likely to be farther away from the SAE estimate than for a MAP home. ${ }^{\left({ }^{(a)}\right.}$

The IOU study makes a novel departure from this general formulation. It decomposes the predicted space heat electricity consumption for a control house (EECTRL) into two components: 1) the predicted consumption had the control house been built to MAP specifications and 2) the difference between this value and the predicted consumption for the house as built. The second term is a measure of predicted electricity savings. Denoting these respectively as EEBASC ${ }_{\mathrm{j}, \mathrm{t}}$ and $\mathrm{EESAV}_{\mathrm{j}, \mathrm{t}}$ the identity is

(a) Behaviorally, takeback effects could contribute to this relationship, but takeback affects on $k_{1}$ and EEBAS, not control houses. Takeback effects occur in efficient homes if the reduced energy service costs cause consumers to "buyback" more electricity because of the price elasticity in the household's demand relation for electric heat. If present, this effect would tend to increase electricity use for space heat. 


$$
\mathrm{EECTRL}_{\mathrm{j}, \mathrm{t}}=\mathrm{EEBASC}_{\mathrm{i}, \mathrm{t}}+\mathrm{EESAV}_{\mathrm{j}, \mathrm{t}}
$$

Inserting this into Equation (6.3) above produces

$$
k W h_{i, t}=a_{0, j}+k_{1} \times \text { EEBAS }_{i, t} \times D_{M}+l_{1} \times\left(\text { EEBASC }_{j, t}+\text { EESAV }_{j, t}\right) \times D_{c}+\ldots
$$

The IOU study estimates this model rewritten as shown in Equation (6.6). This equation " effectively establishes a coefficient restriction that $k_{1}=l_{1}$, but the coefficient on EESAV is estimated freely.

$$
\begin{aligned}
& k W h_{i, t}=a_{0, i}+k_{1} \times\left(\text { EEBAS }_{i, t} \times D_{M}+\text { EEBASC }_{j, t} \times D_{c}\right)+ \\
& I_{1} \times E E S A V_{j, z} \times D_{c}+\ldots
\end{aligned}
$$

\subsection{DISCUSSION OF THE UTILITY STUDY RESULTS}

Table 6.1 compares the MAP savings estimates from the CDA results of the PNL study and the IOU study. For consistency, the estimates are for homes heated with electric furnaces only and the baseline homes is assumed to be built to the new HUD code. For the PNL estimate, the results are from the "Third-Tier Analysis" discussed in Chapter 4. For the IOU study, the results originate from the SAE specification. Under these conditions, the savings estimates reported in the IOU study are only a little over $43 \%$ of the PNL estimates. Given the broad methodological and sample similarities, the disparities are substantial and they can affect significantly the impact assessment of MAP.

TABLE 6.1. Comparative Estimates of MAP Savings ( $\mathrm{kWh} / \mathrm{yr}$ )

\begin{tabular}{||c|c|c||}
\hline Climate Zone & PNL Estimate $^{(\mathrm{a})}$ & IOU Study Estimate \\
\hline CZ1 & 2,524 & 996 \\
\hline CZ2 & 3,522 & 1,513 \\
\hline CZ3 & 4,015 & 1,788 \\
\hline $\begin{array}{l}\text { (a) Lee et al. (1995), Table 4.1 } \\
\text { (b) } \text { RER (1994), Table 3-6 }\end{array}$ \\
\hline
\end{tabular}


Table 6.2 displays the estimated parameters from the IOU study, by heating system type, which lead to the savings estimates presented in Table 6.1. The estimated $k_{1}$ value of 0.92 for electric resistance heat, with no backup heat, suggests that the engineering simulation overstates usage of both MAP and control houses by $8 \%$. The estimated $\mathrm{l}_{1}$, or "realization" rate, of 0.27 implies that the savings estimated by the engineering model overstates savings by a factor of nearly four, compared with the SAE results.

Notwithstanding behavioral elements such as takeback, the study authors view this as a substantial deviation from the a priori expectation that $k_{1}$ and $l_{1}$ should be approximately equal if the simplified engineering model were correct (RER [1994, page 3.22]). The study authors attribute this disparity largely to household takeback effects.

TABLE 6.2. Estimated SAE Parameters from IOU Study

\begin{tabular}{|l|c|c||}
\hline \hline Heating System & $k_{1}$, Heating coefficient & $\mathrm{l}_{1}$, Savings coefficient \\
\hline \hline $\begin{array}{l}\text { Electric resistance, no } \\
\text { backup }\end{array}$ & 0.92 & 0.27 \\
\hline $\begin{array}{l}\text { Electric resistance, wood } \\
\text { backup }\end{array}$ & 0.61 & 0.32 \\
\hline $\begin{array}{l}\text { Electric resistance, other } \\
\text { backup }\end{array}$ & 0.74 & 0.45 \\
\hline Heat pump, no backup & 0.73 & 0.26 \\
\hline \hline
\end{tabular}

However, there are other reasons, related to the SAE model formulation, that may help explain these surprising results. The first two are related to the aforementioned restrictions imposed on the regression coefficients.

First, if the constraint of equal adjustment coefficients for the EEBAS and EEBASC terms is not true, econometric theory indicates that the estimate of $k_{1}$ is biased (Judge et al. [1980]). Our preliminary review suggests that the coefficient is biased downward. The restriction could be tested fairly easily, but judging from the results in Table F-6 of RER (1994) it is probably not a binding constraint. Imposing the constraint, if it is not true; probably introduces a small amount of bias. 
The second observation is essentially an extension of the first. If one were to "unbind" the coefficient on the predicted usage of a control house hypothetically built to MAP requirements, then it should be constrained to equal the coefficient on EESAV by virtue of the implicit decomposition identity in Equation (6.4). The direction of bias in the realization coefficient would be downward if the restriction, if true, were ignored. Applying the constraint would increase the realization rate $\left(I_{1}\right)$, making it larger than the estimated values in Table 6.2.

The third factor that may contribute to the small electricity savings realization rate implied in the IOU study relates to the role played by the EESAV term. The EESAV variable, in part, accounts for factors and end-uses not included explicitly in the model. Thus, it acts like a balancing quantity or a residual, and typically these can be very susceptible to error. In this instance (where engineering models have a known tendency to overstate expected energy savings), the problem may be considerable. This is commonly called an "error-in-variables" problem in econometric modeling. Under the presumption here that it is manifested predominately in only the EESAV variable, econometric theory indicates that least squares estimators of its coefficient are likely to be downward biased (Maddala [1977], and Judge et al. [1980]).

Aside from likely takeback effects, the energy savings realization coefficient in the IOU study's SAE model may suffer from one or more of these three sources of bias. The essential point raised here is that the probable direction of bias on the realization coefficient is downward in all three instances. Our intent is to illuminate this issue and not to declare that one model possesses sources of bias and the other is free from them. Sophisticated CDA models are rarely, if ever, completely free from all sources of bias, .and the PNL specification is unlikely to be an exception in this regard. Instead, since the realization coefficients play such an important role in the SAE methodology, considerable attention on biases here is warranted from a research standpoint. Other than speculation, there is little that can be done to determine the significance of these potential biases without further analysis.

Although the SAE formulation in the IOU study offers significant advantages, the results presented in the study and the points raised above suggest that further research should be conducted to refine the method for this type of application. More investigation of the SAE construct, as well as further estimation of CDA formulations, should be pursued to resolve some of the disparities in the research outcomes to date. 


\subsection{COMPARISON WITH PNL STUDY RESULTS}

A convenient means of partially comparing the results from the IOU study and PNL'S model is through the estimated UECs for the appliance stocks found in manufactured houses in the region. These non-space-conditioning end-uses provide useful benchmarks. Because their load shapes can reflect seasonal variations, they are not entirely independent of space heating estimates. With simultaneous estimation of all the UECs, it is very possible that differences in non-heat end-uses could affect the heating coefficients of both models. If the non-heat results are largely comparable, this would help reduce concerns about different biases in the models. Similarity between the results would also diminish possible concerns about the representativeness and measurement from both sets of sample data.

Table 6.3 compares the estimated UECs from the IOU study with PNL's estimates. In addition, for a broader comparison the table shows the average across several other CDA studies at the national level and for the Pacific Northwest. The latter two are from a compendium'report for the Electric Power Research Institute (EPRI) by Lawrence and Parti (1984). The composite results represent older studies (late 1970s and 1980s), as well as a wide range of housing types.

Generally, the UEC estimates from the IOU study SAE model and our CDA model are similar. For kitchen appliances, the estimates are comparable, albeit the IOU study's estimated refrigerator UEC is less than half of our estimate. Our estimate of the washer/dryer UEC is much smaller than the IOU study estimate; however, both estimates appear to suffer from the problem of multicollinearity. ${ }^{(\mathrm{a})}$ The appliance category of "Auxiliary Pump" includes pool, spa, and well pumps in the IOU study specification, while the PNL model estimated effects of only well pumps and septic pumps. ${ }^{(b)}$

(a) The coefficients for the independently estimated washer and dryer appliances in the IOU study model appear to be simply a linear combination of each other. This can occur when variables are highly correlated, which is probable for complementary appliances such as these.

(b) Recreational equipment pumps such as for pools, spas, and hot tubs were estimated, but the coefficient was consistently negative. This was counter to our a priori expectations and this term was deleted from the final estimating equation. 
TABLE 6.3. Comparison of UEC Estimates (kWh/day)

\begin{tabular}{||l|c|c|c|c||}
\hline \multicolumn{1}{|c|}{ Appliance } & $\begin{array}{l}\text { IOU Study } \\
\text { SAE Model }\end{array}$ & PNL & $\begin{array}{c}\text { National } \\
\text { Composite }\end{array}$ & $\begin{array}{c}\text { Pacific } \\
\text { Northwest } \\
\text { Composite }\end{array}$ \\
\hline Refrigerator & 1.0 & 2.3 & 4.7 & 5.3 \\
\hline Refrigerator (second) & 0.6 & ne/na & 2.8 & NA \\
\hline Freezer & 1.8 & 2.2 & 4.0 & 3.5 \\
\hline Dishwasher & 1.8 & 2.3 & 3.1 & 5.6 \\
\hline Hot Water Heat & 14.0 & 7.8 & 9.1 & 10.5 \\
\hline Clothes Dryer & 4.4 & 0.04 & 2.8 & 5.2 \\
\hline Clothes Washer & .43 & 0.04 & 1.6 & 3.1 \\
\hline Electric Cooking & NA & NA & 2.0 & 3.9 \\
\hline Auxiliary Pumps & $3.1-9.1$ & $1.6-2.7$ & NA & NA \\
\hline Water Bed Heater & 1.3 & 0.4 & NA & NA \\
\hline Personal Computer & NA & 2.8 & NA & NA \\
\hline Miscellaneous & 11.3 & NA & 12.1 & 4.9 \\
\hline \multicolumn{1}{|l|}{ Sources: } & RER (1994); & & Lawrence and & Lawrence and \\
\hline Tables F.2, F.6 & Parti (1984) & Parti (1984) \\
\hline load, but it was slightly negative and not statistically significant. & & & \\
\hline \hline
\end{tabular}

In sum, there appear to be only modest differences between the models in terms of their estimates of specific non-space conditioning end-uses. Therefore, to the extent that estimated UECs for space conditioning and other end-uses are interdependent, differences between our space heat savings estimates and those from the IOU study do not appear to be driven by differences in non-space heat estimates. ${ }^{(a)}$

(a) The thermal-behavior integrated model (TBI) advanced in parallel with the SAE model in the IOU study is probably a closer "substitute" for the CDA specification adopted in our analysis. In this regard, the inferences for the estimated UECs largely still hold, with the exception of the electric water heat estimate. Here, the IOU study TBI model estimates a very low UEC (nearly 
Comparing the IOU study and our study with the other UEC estimates, the differences are typically larger, although fewer pairwise comparisons by appliance types are possible. Generally, the other studies (summarized in the last two columns of Table 6.3) indicate considerably higher UECs for the end-uses presented. This is probably due, in part, to significant appliance efficiency improvements that have occurred in the past decade.

\subsection{CONCLUSIONS}

This chapter highlights the common methodological origins of both the PNL and IOU study approaches. It also discusses differences in the approaches that might account for some of the differences in the results produced by the two methods. Similarities in the samples and variables used in the two approaches minimize the likelihood that characteristics of the samples or variables used in either study could account for much of the difference in the results.

Our examination of the restricted SAE specifications, as used in the IOU study, flags some possible sources of bias. If the biases exist, our review suggests that they would all tend to diminish the apparent realization rate. Because of fundamental differences in the approach, the PNL analysis is not likely to share exactly these same biases. Although biases are likely to be present in the PNL model (Chapter 4 discusses several possible sources), the biases explored here are linked to features unique to the IOU study approach. Consequently, they may be one source of differences between results from the two studies.

Our review of estimated UECs for non-space conditioning end-uses shows that the two studies produce fairly similar results. Because the differences that are observed are relatively small, they do not appear to be a major factor in explaining the substantial differences in energy savings estimated by the two studies.

$42 \%$ lower than our CDA estimates and about $65 \%$ lower than the IOU's study SAE model results). Given the inherent seasonal behavior of this type of usage, the IOU study's higher MAP saving estimates with the TBI specification should be expected. 


\subsection{LEVELIZED COST ANALYSIS DETAILS}

This chapter presents some detailed information on the levelized cost methodology used in this analysis. We assessed the cost-effectiveness of MAP through a procedure specified by Bonneville (BPA 1993). Bonneville determines the cost-effectiveness of demand-side management programs by comparing the levelized price of the energy saved with the levelized avoided cost of Bonneville's alternative electricity resource.

The cost-effectiveness measures we used are described in detail in Bonneville's Energy Conservation Guidebook (BPA 1993). Bonneville's methodology focuses on system cost: a resource's real levelized cost plus or minus four adjustments that quantify indirect cost effects of a resource. These four system cost adjustments account for capacity, seasonality, on/off peak, and resource life, and are determined by Bonneville for every conservation program. Table 7.1 shows the system cost adjustments for MAP.

TABLE 7.1. System Cost Adjustments in $\$ / \mathrm{kWh}(1993 \$)$

\begin{tabular}{|l|l|l|l|l|l||}
\hline $\begin{array}{l}\text { Conservation } \\
\text { Program }\end{array}$ & $\begin{array}{l}\text { Capacity } \\
\text { adjustment }\end{array}$ & $\begin{array}{l}\text { Seasonality } \\
\text { adjustment }\end{array}$ & $\begin{array}{l}\text { On/off peak } \\
\text { adjustment }\end{array}$ & $\begin{array}{l}\text { Resource } \\
\text { life } \\
\text { adjustment }\end{array}$ & $\begin{array}{l}\text { Total } \\
\text { system cost } \\
\text { adjustment }\end{array}$ \\
\hline \hline MAP & -0.03 & -0.18 & -0.02 & -0.62 & -0.85 \\
\hline
\end{tabular}

Bonneville recommends analyzing system costs from two perspectives. The regional system cost is used to determine whether or not MAP, or any other energy efficiency acquisition program, is cost-effective for the region as a whole. Regional system cost is the program's regional real levelized purchase price, including customer contributions, and is adjusted with the factors listed in Table 7.1. This program cost-effectiveness test is basically equivalent to the Total Resource Cost test, which is a benefit-cost analysis that compares the direct costs of a conservation program with the utility's avoided costs. The regional system cost is compared with the program cost-effectiveness limit maintained by Bonneville. This limit is defined as the sum of Bonneville's long-run avoided cost and avoided environmental cost plus a 10\% Regional Act credit for energy efficiency programs. The current cost-effectiveness limit prescribed by the Energy Conservation Guidebook is $4.36 / \mathrm{kWh}$ (1993\$) (BPA 1993). MAP's regional system cost should be equal to, or less than, this cost limit for the program to be cost-effective from the acquisition perspective alone. 
The second cost perspective, Bonneville's system cost, is based on the cost of the energy efficiency program (in this case, MAP) to Bonneville. It is simply Bonneville's real levelized purchase price, adjusted by the factors in Table 7.1. This cost is then compared with the Bonneville Cost Target established in the Energy Conservation Guidebook (BPA 1993). For FY 1994, this target is 2.5\%/kWh (1993\$). The Bonneville publication is not explicit about how this test should be applied to specific programs. For our purposes, we assume that the Bonneville system cost should not exceed this target for MAP to be cost-effective from this perspective.

A real levelized purchase price to be used in the cost-effectiveness analysis expresses all the payments for the resource as an equal payment per kilowatt-hour of energy savings (BPA 1993). The levelized purchase price is calculated by dividing the present value of all program costs by the present value of program savings. To calculate a real levelized purchase price, we must determine how much energy the program saves over the period of time the MAP measures last. Determining an accurate and reliable baseline is a crucial step in estimating program savings. Consequently, we dedicated considerable effort to establishing a sound basis for selecting the baseline used in our analysis.

Using our estimated energy savings and incremental total costs, we calculated the levelized costs of energy savings for MAP homes. We used the Bonneville spreadsheet described earlier to analyze both the regional and Bonneville system cost. To calculate the finance costs and present discounted values we used the following assumptions for Bonneville:

- $\quad 8.35 \%$ finance interest rate

- $3 \%$ real discount rate

- $4 \%$ inflation rate

- 20-year finance term

- 1993 base year.

For the consumer, we used the following assumptions:

- $10 \%$ finance interest rate

- $10 \%$ real discount rate 
- 13-year finance term

- 45-year home life.

It is important to note that the methodology in BPA (1993) does not address costeffectiveness in market transformation programs. Trying to account for the effects of market transformation considerably complicates the assessment of program costeffectiveness. Issues of "free riders" and "free drivers" and how they affect different costeffectiveness tests merit specific attention. Chapter 5 in Lee et al. (1995) discusses some of the cost-effectiveness implications of market transformation associated with MAP. A comprehensive framework for analyzing the cost-effectiveness of market transformation programs does not exist yet and should be a high priority for future programs. 


\subsection{REFERENCES}

Baylon, D. and B. Davis. 1993. Cost-Effectiveness of the Manufactured Housing Acquisition Program (MAP), Ecotope, Seattle, Washington.

Baylon, D., B. Davis, I. Brown, M. Kennedy, M. Lubliner, and S. Onisko. 1991. Manufactured Homes Thermal Analysis and Cost Effectiveness Report, DOE/BP-357384, Bonneville Power Administration, Portland, Oregon.

Belsley, D. A., E. Kuh, and R. E. Welsch (1980). Regression Diagnostics: Identifying Influential Data and Sources of Collinearity. J. Wiley and Sons Inc., New York.

Bonneville Power Administration (BPA). 1993. Energy Conservation Guidebook, Portland, Oregon.

Cahill, J. M., K. G. Ritland, and W. Lin-Kelly. 1992. Description of Electric Energy Use in Single-Family Residences in the Pacific Northwest: 1986-1992, DOE/BP-2018, Bonneville Power Administration, Portland, Oregon.

Fels, M., C. Reynolds, and D. Stram. 1986. Documentation for Heating-Only or CoolingOnly Estimation Program: Version 4.0. Center for Energy and Environmental Studies, Princeton, New Jersey.

Gujarati, D. N. (1988). Basic Econometrics. McGraw-Hill Publishing Co., New York.

Hwang, Ho-Ling. 1989. Assessment of Princeton Scorekeeping Method Space-Heating Estimates Using End-Use Data from the Hood River Conservation Project. ORNL/CON270, Oak Ridge National Laboratory, Oak Ridge, Tennessee.

Judge, G. G., W. E. Griffiths, R. C. Hill, and T-C Lee (1980). The Theory and Practice of Econometrics. John Wiley \& Sons, New York.

Lawrence, A. G., and M. Parti (1984). Survey of Conditional Energy Demand Models for Estimating Residential Unit Energy Cónsumption Coefficients, Prepared for The Electric Power Research Institute, EA-3410, Palo Alto, CA.

Lee, A. D., C. C. Conner, J. E. Englin, D. L. Hadley, R. G. Lucas, N. E. Miller, and W. H. Monroe. 1988. Cost-Effectiveness of Conservation Upgrades in 
Manufactured Homes, PNL-6519, Pacific Northwest Laboratory, Richland, Washington.

Lee, A. D., Z. T. Taylor, D. W. Schrock, L. J. Sandahl, R. I. Chin, and D. C. Kavanaugh. 1995. Impact Evaluation for the Manufactured Housing Acquisition Program (MAP), PNL-10819, Pacific Northwest Laboratory, Richland, Washington.

Maddala, G. S. (1977). Econometrics. McGraw-Hill Publishing Co., New York.

Miller, N. E. and R. G. Pratt. 1990. Thermal Performance of Hood River End-Use Metered Homes, PNL-6595, Pacific Northwest Laboratory, Richland, Washington.

Parti, M. and C. Parti (1980). "The Total and Appliance-Specific Conditional Demand for Electricity in the Household Sector," The Bell Journal of Economics and Management Science, Vol. 11, pp 309-321.

Regional Economic Research (RER). 1994. Regional Impact Evaluation of Manufactured Home Acquisition Program (MAP), San Diego, California.

Roos, C. and D. Baylon. 1993. "Comparison of PRISM Results with Submetered Energy Use Data in Manufactured Homes," Ecotope, Seattle,. Washington.

Sandahl, L. J., A. D. Lee, and R. I. Chin. 1995. Summary of Manufactured Housing Acquisition Program (MAP) Process Evaluation Survey Results, PNL10572, Pacific Northwest Laboratory, Richland, Washington. 